\title{
Getting Married (and Divorced): A Critical Review of the Literature on (De)linking Emissions Trading Schemes
}

Simone Borghesi ${ }^{1}$ and Tong $\mathrm{Zhu}^{2 *}$

${ }^{1}$ European University Institute, Italy and University of Siena, Italy; simone.borghesi@eui.eu

${ }^{2}$ University of Münster, Germany; tzhu@uni-muenster.de

\begin{abstract}
Carbon pricing in general and emissions trading in particular are gaining momentum at the world level. In recent years increasing attention has been devoted to the possibility of linking Emissions Trading Schemes (ETSs). The purpose of the present paper is to critically discuss the main findings emerging from the theoretical economic literature on linking and to draw lessons from the practical experiences of linking (and delinking). Both theoretical and empirical studies suggest that linking ETSs implies strategic interaction and requires substantial coordination between participants. Based on the theoretical literature and on the (un)successful attempts of linking existing ETSs, the present paper provides policy insights into the opportunity of linking in the real world, highlighting the similarity between linking/delinking and getting married/divorced.
\end{abstract}

Keywords: Emissions trading systems; full linking; restricted linking; delinking; carbon markets; cap-and-trade

JEL Codes: F42, G15, H87, Q54, Q58

${ }^{*}$ Corresponding author.

ISSN 1944-012X; DOI 10.1561/102.00000095

(C) $2020 \mathrm{~S}$. Borghesi and T. Zhu 


\section{Introduction}

To date, there are 21 distinct Emissions Trading Systems (ETSs) in operation covering 28 jurisdictions around the world, with 15 systems in preparation or under consideration (ICAP, 2018). As the existing ETSs continue to evolve and a new generation of ETSs emerges, in recent years increasing attention has been devoted to the possibility of linking ETSs.

Linking occurs when two or more ETSs mutually recognize common units or compliance instruments with their respective targets, thus raising both the number of participants and the size of the carbon market. When two systems are linked, companies or other participants in the linked systems (non-regulated entities such as banks, insurance companies and other financial institutions) may trade across the two markets; the compliance instruments they trade in may be used by participating entities in at least one of the systems towards fulfilling their emission targets.

To implement a link, an agreement between two (or multiple) jurisdictions is needed. The nature of this agreement can take different forms, including a "treaty" or an informal agreement. A formal and binding treaty usually requires preliminary negotiations between governments, a political commitment on the modification of the design features that are needed in each ETS, and a final ratification by each partner. Typically, each partner's ETS legislation must be amended to implement the treaty arrangements, especially for the empowerment that allows entities to purchase and use allowances from other ETSs. An informal agreement can be a joint political declaration or a "memorandum of understanding" (MOU). While not legally binding, it creates a common term of reference and aligns expectations. To account for possible future "divorce" between ETS jurisdictions, linking agreement may also include at the outset provisions for delinking. ${ }^{1}$ These can be interpreted as precautionary measures similar to divorce property settlements between spouses. Delinking provisions can affect expectations on whether or

\footnotetext{
${ }^{1}$ As Pizer and Yates (2015) point out, both the Regional Greenhouse Gas Initiative and the California-Quebec agreement included delinking provisions. On the contrary, the European ETS did not specify any provision of that kind, which might now become a problematic aspect in view of the possible withdrawal of the UK from the EU ETS (see section Linking and Delinking in the Real World).
} 
not ETSs will remain linked in the future, as much as the clauses of a divorce settlement can eventually influence the likelihood of divorce itself.

Initial investigations on linking in the literature looked mainly at the feasibility of full linking (e.g., Baron and Bygrave, 2002; Edenhofer et al., 2007; Flachsland et al., 2009a). They analysed the rationale, advantages and risks that a fully-linked market would involve, and concluded that successful full linking would require substantial cooperation and compromise from each participant. In particular, as some studies (e.g., Helm, 2003; Pizer and Yates, 2015) point out, full linking implies accepting the other partner's present and future choices about its future ambition on emissions abatement. Using a game-theoretical approach to examine the strategic motivations underlying the partners' behaviors, several contributions underline the possible existence of freeriding and time-inconsistency problems which may lead partners to adjust national caps in anticipation of linking (e.g., Flachsland et al., 2009a; Helm, 2003). ${ }^{2}$ Given the difficulties that may arise with full linking, a recent tendency in the literature has grown up around the theme of constructing a restricted (sometimes also named "partial" or "incremental") ${ }^{3}$ linkage between two or multiple existing ETSs (e.g., Borghesi et al., 2016; Burtraw et al., 2013; Lazarus et al., 2015; Quemin and de Perthuis, 2019; Schneider et al., 2017), which is considered to be more feasible than full linking. In fact, restricted linking can be considered as a way to "test the waters", an interim step that partners can decide to take before committing to full linking. Adopting the marriage-divorce analogy mentioned above, as Lazarus et al. (2015) have suggested, restricted linking can be seen as similar to moving in

\footnotetext{
${ }^{2}$ On the possible strategic manipulation of carbon policies, see also the more recent contribution by Weitzman (2019) who distinguishes two kinds of free riding problems for ETSs linkage: "primary" free-riding problems concerning the initial definition of caps and allocation of allowances, and "secondary" problems deriving from the misalignment of market stability mechanisms.

${ }^{3}$ Though sometimes used as synonyms, in our view these terms are not exactly the same. For instance, incremental linking indicates the progressive extension of linking agreements across countries, which may possibly lead from bilateral to multilateral linking (Borghesi et al., 2016). This differs from restricted linking as it does not imply conditional or limited recognition of emission units. For the sake of clarity and simplicity, in what follows we will always use the term "restricted" (as opposed to "full") linking throughout this paper.
} 
together rather than getting married, which makes it easier to delink in case the partners (jurisdictions) decide to separate later on.

While linking is attracting increasing attention among both scholars and policy-makers, little linking has occurred in practice so far. The California-Québec joint cap-and-trade programme is the most prominent but also one of the few examples of linking at the moment. ${ }^{4}$ One possible explanation for the lack of linking experiences is that linking requires long negotiations to align the numerous technical aspects characterizing an ETS. Since most ETSs are relatively new in the landscape of the overall climate policy instruments, more time is needed for linking to emerge. Another possible reason, as (Flachsland et al., 2009b) pointed out, is that international emissions trading may not be welfare-enhancing for some countries due to market distortions (e.g., non-competitive energy markets, pre-existing energy taxes, or fuel subsidies) and negative terms-of-trade effects, which prevent their linking with other countries. Finally, even when linking would be mutually beneficial, the costs of linking may be perceived as being higher than the correspondent benefits. This is particularly the case when risks and uncertainties are considered (Dellink et al., 2008; Kersting, 2018). ${ }^{5}$

The aim of the present paper is to provide a critical review of the economic literature on the main findings of alternative forms of (full versus restricted) linking and on the (de)linking experiences in the realworld scenario. To the best of our knowledge, the current work is the first one to examine both the ex-ante theoretical literature and the ex-post evaluations of the real-world examples of linking and delinking available so far. This allows to provide a comprehensive investigation of an issue that has provoked heated debate among scholars and policy-makers and between proponents and opponents of linking. ${ }^{6}$

\footnotetext{
${ }^{4}$ See section Linking and Delinking in the Real World for other examples of linking.

${ }^{5}$ See Wood et al. (2013) and Heindl et al. (2014) for studies using stochastic models to assess how uncertainty affects linking among asymmetric countries with different carbon policies. See also Caillaud and Demange (2017) for a formalization of uncertainty as a fundamental determinant of climate policy and of its impact on linking ETSs of different regions.

${ }^{6}$ For example, while some scholars (e.g., Doda and Taschini, 2017a,b) regard linking carbon markets as a suitable way to mitigate climate change, others (e.g., Green, 2017; Green et al., 2014) have harshly criticized it. In their opinion, in the absence of a central carbon bank that manages allowances and prices, linking
} 
The rest of the present paper is organized as follows. Types of Linking section outlines the possible ways of linking, Advantages and Disadvantages of Linking section discusses the main pros and cons of linking, Theoretical Studies on Linking and Delinking section investigates the theoretical literature on linking (and delinking) focusing particular attention on the economic and environmental implications of each type of linking method. Linking and Delinking in the Real World section studies the attempts at linking carbon markets pursued until now, looking at both successful and unsuccessful ones. Concluding Remarks on Linking (and Marriages) section concludes the paper discussing the similarities between (de)linking and (divorces) marriages, and drawing some policy implications deriving from the analysis.

\section{Types of Linking}

Linking can take different forms. According to several authors (e.g., Borghesi et al., 2016; Lazarus et al., 2015; Quemin and de Perthuis, 2019; Schneider et al., 2017), linking methods can be broken down into three categories:

\section{- Unilateral/bilateral/multilateral}

Unilateral linking is a one-way form of linking where entities from one ETS can buy and use emission allowances from another ETS in order to achieve their domestic reduction goals, but not vice versa. Bilateral linking implies mutual recognition of units between ETSs, while multilateral linking involves a similar recognition across multiple ETSs.

\section{- Direct/indirect}

Direct linking allows regulated entities in the linked ETSs to purchase and use each other's allowances for compliance with their domestic emissions reduction obligations. An example of this is

adds just regulatory complexity making carbon markets more interdependent, and therefore also more sensitive to changes elsewhere. Doda and Taschini (2017b), on the contrary, argue that a central carbon bank is not necessary for linking and show that under specific conditions linking can bring about economic advantages. 
the linkage between the ETS of California and Québec. The same allowance units, named California carbon allowances (CCAs), are valid in both jurisdictions and the regions have been holding joint quarterly auctions since $2014 .{ }^{7}$ Indirect linking implies that both (multiple) ETSs allow the usage of emission units issued from a third party. A common form of indirect linking is through mutually recognized offset credits, such as the Certified Emission Reductions (CERs) from the Clean Development Mechanism $(\mathrm{CDM})$ and the Emission Reduction Units (ERUs) from the Joint Implementation (JI).

\section{- Full/restricted}

Full linking means that two (multiple) ETSs recognize the usage of emission units issued by the other partner(s) without any restrictions and conditions. Correspondingly, restricted linking indicates a conditional and limited recognition of emission units from the other(s). Units used in each ETS are still recognized as being valid in terms of compliance among the linked programmes, but with some restrictions.

While the first two classifications (unilateral/bilateral/multilateral and direct/indirect) concern the direction and channels of linking, the third one (full/restricted) is about the degree of linking between partners. In this respect, as Lazarus et al. (2015) have pointed out, one can identify a wide range of intermediate options moving from no linking (or autarky) to full linking, that is: (i) recognition of other (non-ETS) mitigation programmes, (ii) incremental alignments (also called "linking by degrees" following Burtraw et al., 2013), (iii) indirect linking (which implies no mutual recognition of allowances), and (iv) restricted linking (which implies partial or restricted recognition of allowances). In this paper, we will focus mainly on this last category that has attracted

${ }^{7}$ The legal linking agreement between California and Québec can be found here: https://www.arb.ca.gov/cc/capandtrade/linkage/ca_quebec_linking_ agreement_english.pdf

${ }^{8}$ Notice that the three categories of linking described here (unilat$\mathrm{eral} /$ bilateral/multilateral, direct/indirect, full/restricted) can partially overlap. For instance, unilateral linking can be seen as a restricted linking method, in which one jurisdiction limits the imports of emission allowances to zero, while the other allows unlimited imports (Lazarus et al., 2015). 
particular attention in the literature and on the alternative ways it can be implemented.

As for restricted linking, four different methods have been proposed to date (Lazarus et al., 2015; Quemin and de Perthuis, 2019; Schneider et al., 2017), namely: (i) quantitative restrictions; (ii) border taxes on allowances transfer; (iii) exchange rates; and (iv) discount rates.

- Quantitative restrictions (or quotas)

Quantitative restrictions restrict the number or the type of units from other ETSs that can be used for domestic compliance. Restrictions can be set at the jurisdiction level, from either side of allowances transfer, in order to limit the overall (or net) import or export of allowances. Alternatively, restrictions can be set at the entity level, i.e. limiting the number of allowances that can be exported or imported by individual entities.

- Border taxes on allowances transfer

A border tax occurs when there is a cross-jurisdiction transfer of allowances. Due to differences in domestic taxation systems and depending on whether an emissions allowance is classified as good or as service, multiple tax rates can be applied to traded emissions allowances. Border taxes can be imposed by either the exporting jurisdiction or, more typically, by the importing jurisdiction. ${ }^{9}$

- Exchange rates (or trading ratios)

The exchange rate adjusts the value of units transferred between jurisdictions. Within the Networked Carbon Markets (NCM) initiative promoted by the World Bank Group, several studies have examined how this mechanism could be implemented (e.g., Füssler and Herren, 2015; Füssler et al., 2016; Marcu, 2015). In particular, the NCM proposes to connect carbon markets through independent rating agencies and systems. According to the World Bank

\footnotetext{
${ }^{9}$ One example of border taxes on cross-jurisdiction transfers is provided by the export of Chinese CERs (Quemin and de Perthuis, 2019). China has been the only host country to systematically impose specific levies on China-based CDM projects in addition to income corporate taxes. The objective was to split the CDM rent between the government and projects owners (Liu, 2010).
} 
proposal, the latter would rate environmental integrity and climate change mitigation value of carbon assets in the international markets and then convert ratings into carbon exchange rates. All international trading would then be registered in an International Settlement Platform that would possibly act as clearing house for the whole system. ${ }^{10}$

\section{- Discount rates}

Similarly to the case of exchange rates, discount rates also involve a numerical ratio. For instance, if ETS A applies a 20\% discount to allowances purchased externally, then 100 allowances purchased from the linked ETS B are equivalent to 80 domestic allowances in ETS A. In this case, therefore, 1.25 (i.e. 100/80) allowances purchased through linked ETSs are required to redeem one unit of domestic allowance. ${ }^{11}$ Notice that discount rates applied by linked ETSs need not be the same but may differ across partner(s). Therefore, discount rates do not need to be set as reverse ratios between two linked systems, as occurs in the case of exchange rates.

\section{Advantages and Disadvantages of Linking}

It is possible to identify several potential advantages that may prompt countries to look for a partner jurisdiction to match with. In particular, linking existing ETSs can bring a number of economic benefits, which can be grouped into three main areas (Flachsland et al., 2009a; IETA, 2006). First, creating a larger carbon market through linking expands opportunities for emitters to internalize pollution at the lowest cost.

\footnotetext{
${ }^{10}$ See Zaman and Hedley (2016) for an in-depth discussion of the regulatory framework that is needed for networking carbon markets and how existing trading arrangements and regulatory frameworks might be used to start the networking process.

${ }^{11}$ Existing examples of discount rates are mainly for offsetting. For example, the American Clean Energy and Security Act of 2009 states that an entity needs to turn in 1.25 tons of offsets for a compliance obligation of one ton, effectively implementing a $20 \%$ discount rate. Please refer to Chung (2007), Schneider (2009), Erickson et al. (2014), and Warnecke et al. (2014) for a discussion of discount rates in the context of offset mechanisms.
} 
Covered entities have access to a wider array of emission abatement opportunities, leading to the use of the most efficient options. Overall compliance costs can be decreased and cost-effectiveness increased (Jakob et al., 2014). ${ }^{12}$ If this is the case, theoretically, a global carbon market could be seen as the ultimate solution to reducing global emissions and achieving the overall objective of keeping global warming below two degrees Celsius (Ranson and Stavins, 2012).

Furthermore, linking existing ETSs can increase market liquidity and reduce potential market manipulation. An asset is deemed (il)liquid if it can(not) easily be sold or exchanged for cash within a short amount of time. ${ }^{13}$ By expanding market size, linking obviously increases market liquidity as it augments the numbers of potential buyers and thus the chances for the seller to cash-in the allowances. An expanding market with higher trading volumes and quantity can reduce the possibility of market monopoly power which could impair the efficiency of emissions trading (Fershtman and de Zeeuw, 2013). A large and active trading market could also spur the development of financial instruments. Entities can benefit from well-developed climate financial systems, for example, by hedging price risks.

Thirdly, linking existing ETSs can lead to convergence of carbon prices, which can reduce or eliminate the distortions hindering competitiveness and the possibility of carbon leakage towards jurisdictions with laxer (or no) ETSs. ${ }^{14}$

Other scholars have also brought up several potential political and administrative benefits (Bramley et al., 2009; Burtraw et al., 2013;

${ }^{12}$ Following Lazarus et al. (2015, p. 15), for a given abatement outcome costeffectiveness can be defined as total abatement costs in both jurisdictions under no linking divided by total abatement costs in both jurisdictions under linking.

${ }^{13}$ The liquidity of a good or commodity is strictly connected but logically different from its fungibility. A good is said to be liquid if it can be easily exchanged for money or another good, whereas it is fungible if one unit of the good is substantially equivalent to another unit of the same good, so that each unit is interchangeable and therefore indistinguishable from other units. Under full linking allowances of the two jurisdictions are mutually recognized as valid compliance instruments in either jurisdiction and can be traded as the same commodity. Under restricted linking, instead, the allowances of each jurisdiction continue to be traded as different commodities (see Lazarus et al., 2015).

${ }^{14}$ See Bohringer et al. (2018) for an interesting analysis of the possible carbon leakage effects of unilateral climate policies accounting for climate coalitions of different size. 
Füssler et al., 2016; Heitzig, 2013). Linking ETS can enhance domestic climate policy acceptance in each participating jurisdiction because it constitutes a multicultural commitment to the common goal of emission reduction. Additionally, the linkage of ETSs can promote mutual learning in emissions trading and reinforce cooperation across jurisdictions. ${ }^{15}$ In particular for smaller economies/markets, information sharing and experience exchanging with relatively large and mature ETSs could be valuable.

Despite a number of potential benefits, however, linking existing ETSs also entails significant challenges and obstacles. ${ }^{16}$ They can be summarized as policy issues, regulatory issues, and distributional issues. First of all, the policy goals each individual programme prioritizes may not be shared by the linked programme. For example, under the circumstance of unbalanced mitigation stringency between two parties, the cap in ETS X may be substantially laxer than that in ETS Y, so that linking programmes can constitute a "watering down" of ambition for ETS Y, undermining the region's climate policy goals.

The regulatory issue refers to the fact that each ETS regulator loses some operational control (Flachsland et al., 2009b). Regulators in each programme lose some of their authority on their own ETS, as they have to agree on substantial changes. Differences in the design of the linked ETS, whether these differences emerge pre- or post-linkage, could undermine the environmental integrity of one of the linked systems leading to price volatility and/or low carbon prices. For example, if a party to a linking agreement alters limits on offsets use, it will affect the carbon price in the emissions trading system of the other party. ${ }^{17}$ Hence, for ETSs to be "linkable" without undermining their respective environmental integrity, their design features should be compatible.

As for the distributional issue, if the average allowance price in ETS $\mathrm{X}$ is lower than in ETS Y, linking the two programmes will provoke a

\footnotetext{
${ }^{15}$ For this purpose, since 2017 the European Union regularly holds annual meetings among regulators of some of the main ETSs (California, Canada, China, EU, Quebec, Switzerland, and New Zealand) and carbon market experts from around the globe to exchange experiences from emissions trading systems put in place by different countries and regions and thus enhance collaboration (European Commission, 2019).

${ }^{16}$ See Flachsland et al. (2009b) for a systematic analysis of the benefits and disadvantages of linking which stresses possible counter-arguments to the conventional gains-from-trade arguments in favor of linking.

${ }^{17}$ Please refer to Fell et al. (2011) for further information on offsetting.
} 
redistribution between winners and losers: Those who were able to sell allowances in ETS Y will now be undercut by sellers in ETS X, who can sell at lower prices. The agents who have to buy allowances, however, will be able to do so more cheaply. As a consequence, linking may have a differential impact on the competitiveness of the industries (and thus also on employment) of the linked jurisdictions. Indeed, companies in the high-price jurisdiction will buy allowances in the low-price jurisdiction, which reduces their costs and thus increases their competitiveness. The opposite obviously applies to buyer companies in the low-price jurisdictions with potential adverse effects on their competitiveness. Production may therefore shift from low-price jurisdictions to high-price jurisdiction. In addition, it may also discourage firms in the high-price jurisdiction from abatement innovation (Fershtman and de Zeeuw, 2013). However, this differential effect (which favours buyers in the high-price jurisdiction) can be partially offset by the trade-related financial flows from the high- to the low-price jurisdiction. Moreover, the ETSs in the two jurisdictions are likely to be aligned to make them "linkable", well before linking actually occurs. Therefore, the allowance price differential is unlikely to be high ex-ante, so that one can reasonably expect a limited differential effect on the competitiveness of the industries in the linked jurisdictions. ${ }^{18}$

Finally, another crucial aspect which is strictly related to the distributional issue concerns the way revenues from selling allowances are used once linking is implemented. In this regard we can distinguish revenues deriving from auctioning allowances in the primary market from those raised on the secondary market. In the first case, by increasing the market size and the numbers of competitors participating to the auctions, linking can potentially raise revenues for both jurisdictions. ${ }^{19}$

\footnotetext{
${ }^{18}$ As argued by Quemin and de Perthuis (2019), although a large allowance price gap would theoretically increase potential gains from linking, this would also raise concerns about rent transfers which would make linking politically unpalatable or unfeasible in practice.

${ }^{19}$ In the Californian cap-and-trade system, for instance, revenues for the government from allowances auction increased rapidly since the end of 2014, after linking with Québec. The Californian cap-and-trade system was estimated to generate USD 12.5 billion revenues for CA government between 2012 and 2019, almost all of which after linking (cf. Figure 1 in CCI (2020) showing the pattern of annual auction incomes in California over the whole period). The Québec cap-and-trade programme was estimated to raise USD 2.23 billion by the end of 2018 (Santikarn
} 
Such revenues go directly to the governments that can use them for both environmental and non-environmental purposes, ranging from support of low-carbon technologies to redistribution policies and reduction of budget deficit. In the second case, revenues accrue to single agents (the allowance suppliers in the secondary market); government entries will be affected only indirectly through, for instance, income corporate taxation and commodity taxation depending on the jurisdictions' taxation systems (Carmody, 2019).

The way revenues from selling allowances are used by each jurisdiction obviously depends on its internal priorities and on specific economic circumstances. ${ }^{20}$ This choice may heavily affect the jurisdiction's economic growth, inequality, low-carbon innovations and, therefore, also the overall perception of the net benefits of linking. ${ }^{21}$ In our opinion, ear-marking these revenues could provide a very powerful signal both within the jurisdiction and to the potential linking partners on the commitment of the regulator to reaching the environmental targets.

\section{Theoretical Studies on Linking and Delinking}

Although the topic is relatively new, there is a large and growing number of theoretical studies exploring linking. On the contrary, the literature on delinking is still very scant so far. In order to provide a comprehensive view of the ex-ante theoretical contributions in the field, we document representative studies published after 2000. A summary of the main results emerging from each contribution is presented in Table 1 in which studies are presented in chronological order, along with journal information, regions involved, focus on linking or delinking, types of linking being examined, methodology and main conclusions.

et al., 2019). See section The California-Québec Joint Cap-and-Trade Programme for further discussion on the consequences of the California-Québec linking.

${ }^{20}$ For instance, in the EU ETS (a potential partner for linking with other jurisdictions in the years to come), Member States are requested to use at least half of the revenues for climate and energy purposes such as energy efficiency, renewables, research and sustainable transport. Auctioning in the EU ETS has generated about $\$ 58,968$ million since 2009 (ICAP, 2020). Most of the revenues (more than $80 \%$, well above the recommended $50 \%$ ) have been used or are planned to be used for climate and energy purposes (cf. https://ec.europa.eu/clima/policies/ets/auctioning_en).

${ }^{21}$ See Pezzey and Jotzo (2012) for a model on the welfare benefits of revenue recycling under different policy regimes (tax versus trading). 


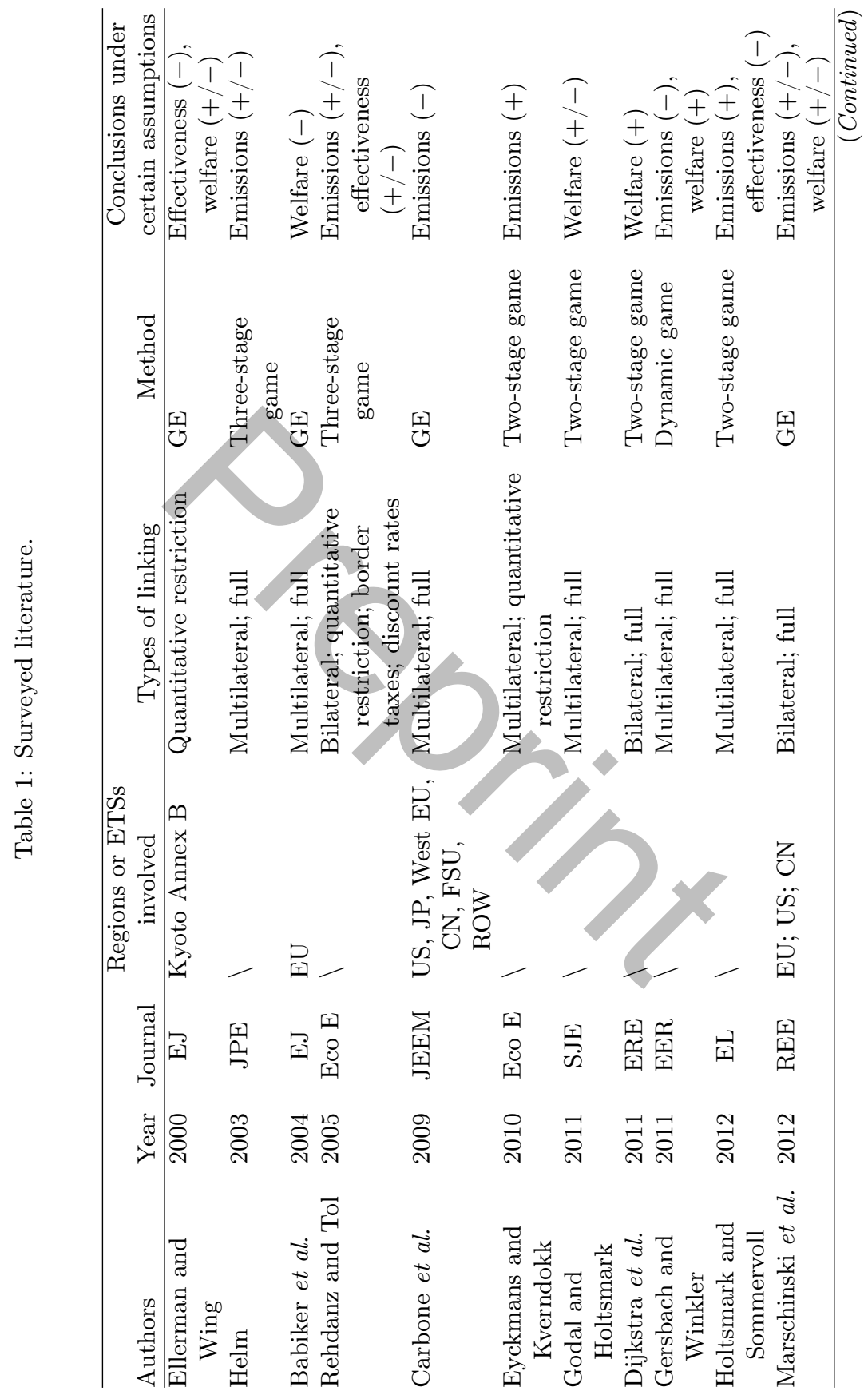




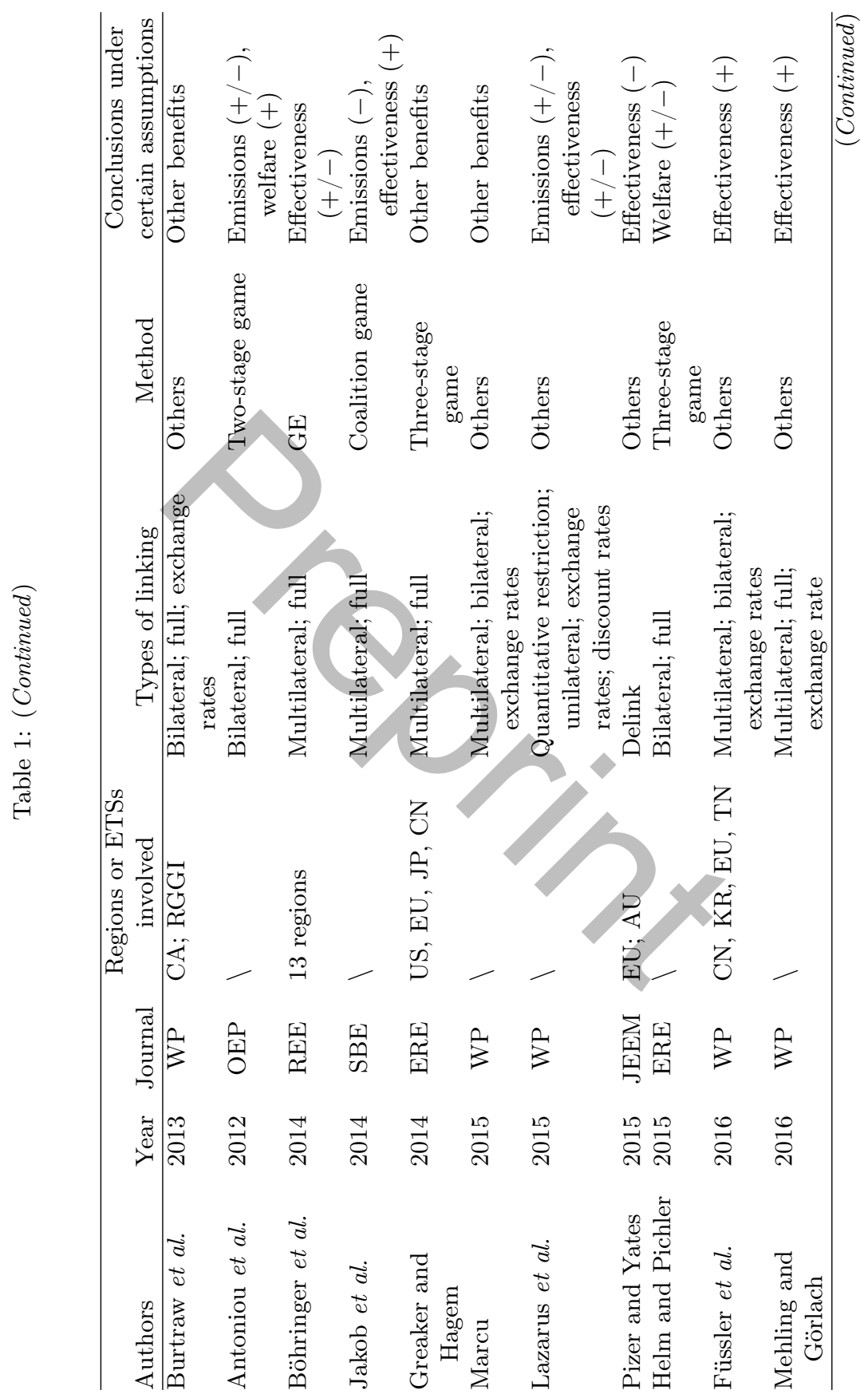




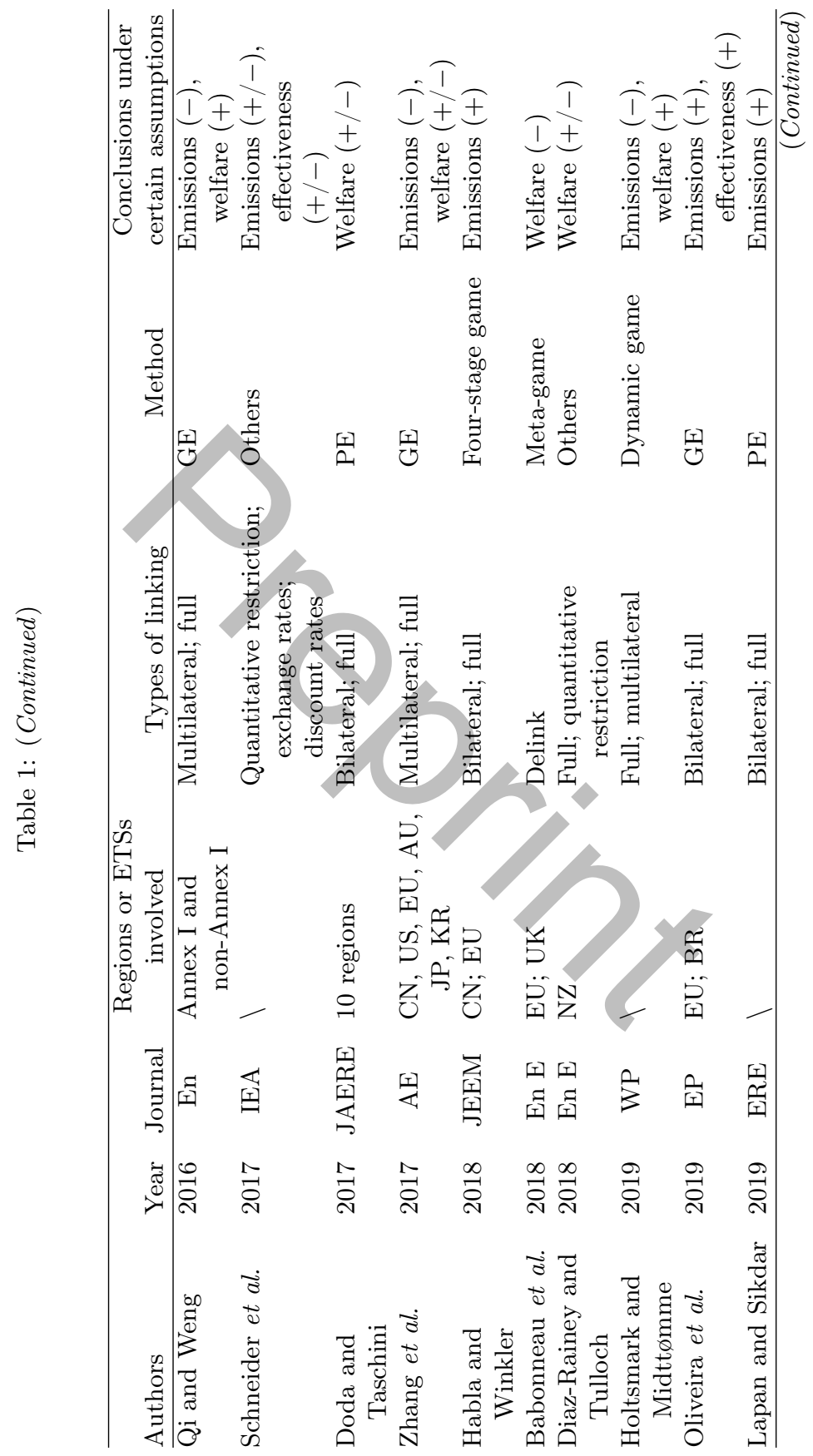




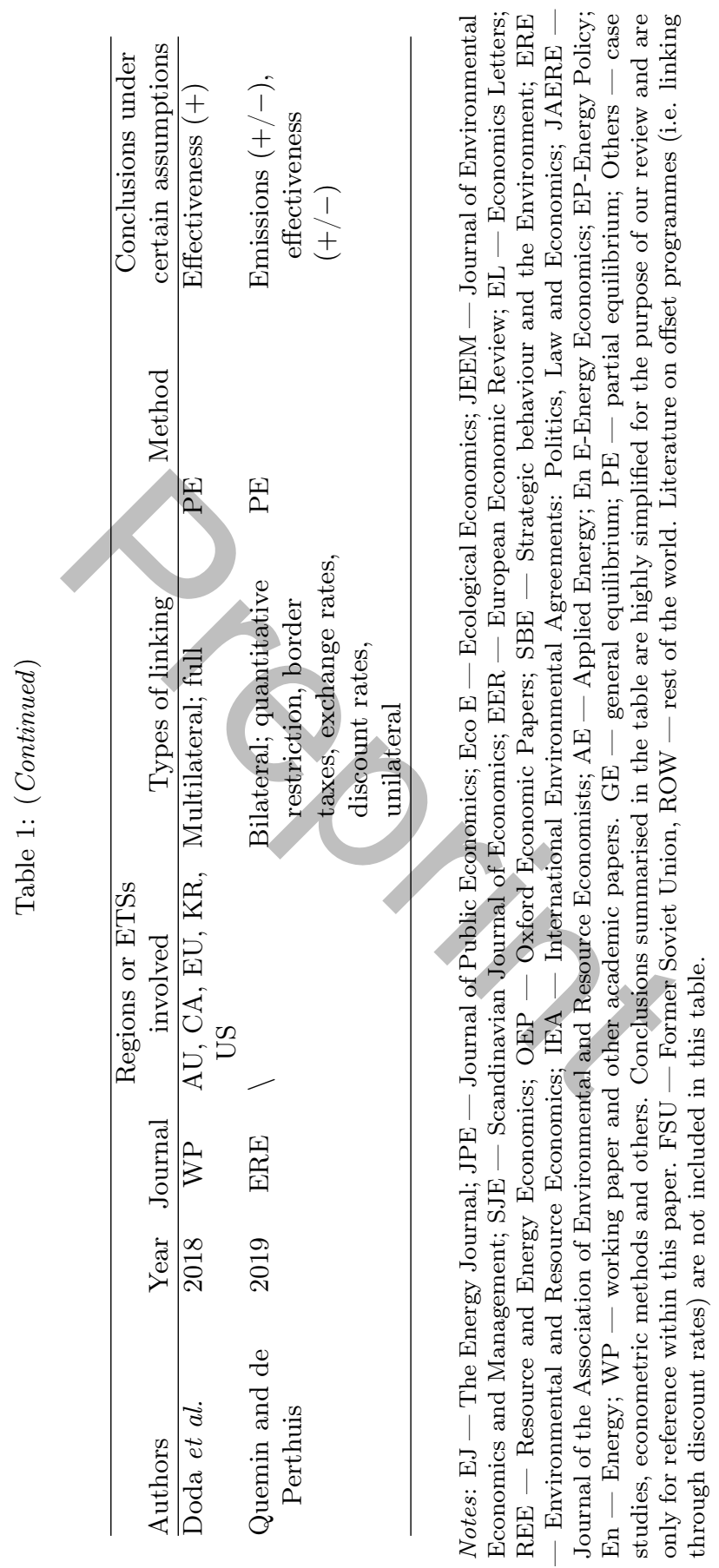


Table 1 reveals that game theory and general equilibrium models tend to be popular methods in the field. As emerges from the table, the literature finds contrasting results. This can probably be ascribed to the fact that the model setting differs across individual studies. For example, Lazarus et al. (2015) and Schneider et al. (2017) conduct their analysis assuming a linear abatement cost function, while Quemin and de Perthuis (2019) use a quadratic cost function.

Another model setting that can heavily affect the observed results, concerns the distinction between static or short-term and dynamic or long-term effects. In the short-term, capital is fixed and firms do not modify their technologies. In the long-term, instead, new investments and technological innovation - driven by changes in allowance prices can take place. Both the static and dynamic perspectives can give important insights. However, as Fuss et al. (2018) have pointed out, the dynamic analysis is particularly important since carbon trading aims at achieving a long-term cap rather than a series of short-term (e.g., annual) caps. Thus, for instance, by modifying carbon prices, linking may affect operators' expectations on investment returns in the long run, leading to changes in their investment decisions. Similarly, delinking provisions and other linking designs may influence expectations on the capacity of linking agreements to hold over time, which may lead operators to revise their plans and modify their market behavior. Unfortunately, the literature has partially overlooked this important distinction between static and dynamic effects so far and - if we exclude a few notable exceptions (e.g., Holtsmark and Midttømme, 2019; Pizer and Yates, 2015) - most of the studies do not explore the long-run consequences of (de)linking on the aspects mentioned above.

\section{The Economic and Environmental Implications of Linking}

Different ways of (full versus restricted) linking can have very different implications from both the economic and environmental viewpoints. In this section we document the findings of the theoretical literature on the expected effects of each form of linking using three main criteria that have been often adopted in the literature (cf. Lazarus et al., 2015; Quemin and de Perthuis, 2019; Schneider et al., 2017): cost-effectiveness, market liquidity, and emission reductions. We can thus distinguish two dimensions of the analysis: (i) the existing linking approaches (full versus 
Table 2: Summary comparison of alternative linking methods (relative to no-linking).

\begin{tabular}{|c|c|c|c|}
\hline \multirow[b]{2}{*}{ Methods } & \multicolumn{2}{|c|}{ Economic implications } & \multirow[b]{2}{*}{ Abatement implications } \\
\hline & Cost-effectiveness & Liquidity & \\
\hline Full linking & $\begin{array}{l}\text { Maximized } \\
\text { cost-effectiveness }\end{array}$ & Increased liquidity & No change \\
\hline $\begin{array}{l}\text { Quantitative } \\
\text { restrictions }\end{array}$ & $\begin{array}{l}\text { Enhanced } \\
\text { cost-effectiveness }\end{array}$ & $\begin{array}{c}\text { Increased liquidity } \\
\text { but much less so } \\
\text { than full linking }\end{array}$ & No change \\
\hline $\begin{array}{l}\text { Border taxes } \\
\text { on } \\
\text { allowances } \\
\text { transfer }\end{array}$ & $\begin{array}{l}\text { Enhanced } \\
\text { cost-effectiveness }\end{array}$ & $\begin{array}{c}\text { Increased liquidity } \\
\text { but much less so } \\
\text { than full linking }\end{array}$ & No change \\
\hline $\begin{array}{l}\text { Exchange } \\
\text { rates }\end{array}$ & $\begin{array}{l}\text { Enhanced } \\
\text { cost-effectiveness } \\
\text { within the } \\
\text { effective interval } \\
\text { and below the } \\
\text { effective interval; } \\
\text { Reduced } \\
\text { cost-effectiveness } \\
\text { above the } \\
\text { effective interval }\end{array}$ & $\begin{array}{l}\text { Increased liquidity } \\
\text { (similar to full } \\
\text { linking) }\end{array}$ & $\begin{array}{l}\text { Increased total } \\
\text { abatement within } \\
\text { the effective interval; } \\
\text { Reduced total } \\
\text { abatement outside } \\
\text { the effective interval } \\
\text { (no matter whether } \\
\text { below or above the } \\
\text { effective interval) }\end{array}$ \\
\hline $\begin{array}{l}\text { Discount } \\
\text { rates }\end{array}$ & $\begin{array}{l}\text { Enhanced } \\
\text { cost-effectiveness }\end{array}$ & $\begin{array}{c}\text { Increased liquidity } \\
\text { but much less so } \\
\text { than full linking }\end{array}$ & $\begin{array}{c}\text { Increased total } \\
\text { abatement }\end{array}$ \\
\hline
\end{tabular}

restricted) suggested in the literature, and (ii) the three main criteria (cost-effectiveness, market liquidity, and abatement implications) used to evaluate the expected performance of each kind of linking. These two dimensions correspond to the rows and columns of Table 2, respectively, which summarises the main findings emerging from the literature.

We first consider the economic and environmental implications of full linking that is taken as baseline, and then we evaluate how different forms of restricted linking are predicted to perform with respect to the benchmark.

\section{- Full linking}

In the case of autarky (i.e. when there is no linking), allowance prices in individual systems differ from each other due to different mitigation 
objectives and different abatement capabilities. In the opposite case in which ETSs are fully linked, market prices converge to the same level across linked jurisdictions through allowance trading. The high-price jurisdiction will buy a certain number of allowances from the low-price jurisdiction. This implies that the high-price (low-price) jurisdiction will abate less (more) as compared to autarky. It follows that - along with allowance transactions - a certain number of abatement activities will be "transferred" across jurisdictions. Overall abatement remains the same as under the no linking scenario, while the total costs for achieving an overall abatement outcome are reduced across jurisdictions, thus improving the cost-effectiveness of the joint systems (the first evaluation criterion mentioned above).

Although the low-price jurisdiction exports allowances and hence abates more as compared to autarky, the financial payment received by the low-price jurisdiction shall be higher than the cost of the additional abatement for domestic entities. This generates an economic surplus for exporting entities. At the same time, the payment made to acquire additional allowance abroad is smaller than the opportunity costs of abatement for importing entities. As a result, linking creates an economic surplus for importers in high-price jurisdictions as well. Therefore, by linking their domestic ETSs rather than staying on their own, both jurisdictions may be better off.

When ETSs are fully linked, market liquidity (the second criterion used to evaluate linking) is enhanced by the increased number of traders and allowance transfer. However, price volatility and economic shocks may spread through the linked systems due to the high liquidity level (Doda and Taschini, 2017a). Linking may end up enhancing rather than reducing price volatility for the linked jurisdiction with initially lowprice volatility: as argued by Doda and Taschini (2017a), however, this increased price volatility does not necessarily leave the jurisdiction worse off as compared to the case of autarky. Besides, financial instruments are more likely to be developed in a larger trading market. Entities can benefit from the well-developed climate financial systems through, for example, hedging price risks while promoting investments in green technology (Holtsmark and Midttømme, 2019).

Finally, as far as abatement is concerned, full linking should not, in theory, change the total amount of abatement activities. However, some studies argue that linking might have negative implications for 
abatement activities due to the possible mismatch between the mitigation ambitions of the involved jurisdictions. In particular, Helm (2003) one of the earliest studies in the literature on this issue - finds that linking may encourage "free-riding" behavior in a static non-cooperative game by inducing linked jurisdictions to alter their emissions cap: ${ }^{22}$ when allowances can be traded across different jurisdictions, less (more) environmentally concerned countries are likely to choose more (less) allowances so that the overall effect of linking on emissions is ambiguous a priori and may also lead to higher emissions. A similar conclusion is reached by Rehdanz and Tol (2005) using a static two-country threestage game model. ${ }^{23}$ However, the few more recent studies that adopt a dynamic framework (Gersbach and Winkler, 2011; Holtsmark and Midttømme, 2019) reach opposite and much more optimistic conclusions on the abatement effects of linking. ${ }^{24}$ In particular, using a dynamic game theory model, Gersbach and Winkler (2011) propose an international trading market among homogeneous countries where a proportion of permits is auctioned, and part of auction revenues are refunded to participants in multiple periods. Refunding in future periods reduces greatly the incentive of over-insurance. The authors find that with refunding countries ultimately tighten the issuance of permits, and are better off compared to international markets without refunding. Furthermore, utilizing a two-stage dynamic game theory model, Holtsmark and Midttømme (2019) find that a fully-linked market can drastically reduce emissions and raise investments in green technology. Specifically, the authors point out that in a dynamic context linking may create a voluntary emissions reduction mechanism that is not captured in a

\footnotetext{
${ }^{22}$ The existence of an incentive to free-riding has been pointed out also in early studies on global climate agreements using coalition games (Barrett, 1994; Carraro and Siniscalco, 1993; Hoel, 1992). While that literature on climate coalitions did not take emissions trading schemes into account, those seminal contributions can be regarded as particularly useful being in a way the forerunners of more recent theoretical studies on the stability and profitability of the possible linking agreements (e.g., Doda and Taschini, 2017a).

${ }^{23}$ Other contributions (e.g., Carbone et al., 2009; Holtsmark and Sommervoll, 2012) use static game models performing numerical simulations to evaluate the efficacy of international trade in carbon emissions permits.

${ }^{24}$ Finus (2008) and Calvo and Rubio (2013) provide literature reviews on game theory models and dynamic games of international environmental agreements, respectively.
} 
static framework. Indeed, if one country withholds its emission permits today this will increase the permits price in all linked countries, inducing green energy producers in all countries to increase their investments in renewables. This will increase in its turn the available durable production capacity for green energy in the future, thus lowering also the permits allowance in all linked countries when emission permits will expire. Thus, by including investments in durable renewable energy capacity, the authors show the existence of strategic complementarity between permit issuance of linked countries.

\section{- Quantitative restrictions (or quotas)}

A quantitative restriction will obviously be effective only if it is binding, that is, if the limitation of allowances transferring across ETSs is lower than the traded amount under full linking. Quantitative restrictions entail intermediate results between the two extreme scenarios, namely no linking (i.e. maximum possible restriction) and full linking (i.e. no restriction), with marginal economic gains increasing as we move from the former to the latter. In the case of quantitative restrictions, price differentials between two jurisdictions remain, though they are smaller than those under the no linking scenario. Cost-effectiveness is not fully achieved under the restricted linking scenario. Hence, there is an overall welfare loss as compared to full linking. It is noteworthy that quantitative restriction generates a scarcity rent. The latter is captured by exporting entities in the low-price jurisdiction if the restriction is set as an export control, or more likely, by importing entities in the high-price jurisdiction if import is limited (Ellerman and Wing, 2000; Quemin and de Perthuis, 2019). ${ }^{25}$ Under certain circumstances, the gainer of this scarcity rent can be better off as compared to the full linking scenario. ${ }^{26}$

${ }^{25}$ For example, for import control, the restriction can be set as a percentage of the compliance obligations by entities in the high-price jurisdiction. It limits the demand of allowance from the importer side. As entities in the low-price jurisdictions compete to sell allowances to the high-price jurisdiction, the transaction price is likely to settle at a level that is infinitely close to the original price of the low-price jurisdiction. Hence, entities in the high-price jurisdiction capture the scarcity rent.

${ }^{26}$ Different studies identify different thresholds for this to happen depending on specific model assumptions. Using a computable general equilibrium model, Ellerman and Wing (2000) study quantitative restrictions on imports and find that 
Quantitative restrictions will still increase market liquidity as compared to the autarkic case in which each jurisdiction runs on its own ETS. But the enhancement of liquidity is obviously not as strong as that under full linking. Indeed, under quantitative restrictions, allowances from different jurisdictions cannot be traded as identical commodities, therefore they are not fully fungible. As under full linking, some abatement activities are transferred across jurisdictions but the number of allowances transferred is less than that under full linking. The total amount of abatement activities jointly performed by linked jurisdictions is predicted to remain the same as under the full linking and no linking scenarios.

\section{- Border taxes on allowances transfer}

As in the case of quantitative restrictions, border taxes on allowances transfer reduce overall abatement costs across jurisdictions, compared to no linking but are less cost-effective than full linking. Border taxes can be implemented by either the importing or the exporting jurisdiction. The jurisdiction that implements border taxes is unambiguously detrimental to the other jurisdiction. Under certain circumstances (e.g., a small importing tax, cf. Quemin and de Perthuis, 2019), the jurisdiction implementing border taxes turns out to be better off compared to the full linking scenario because of the tax revenue.

Market liquidity under border-tax linking is predicted to be between the case of full linking and autarky. To each tax rate there corresponds a unique number of allowances that will be traded given the difference in pre-linking prices between jurisdictions (Quemin and de Perthuis, 2019). Tax rates above a certain level brings the equilibrium back to autarky, and no cross-border allowances transfer will occur. Under bordertax linking, allowances from different jurisdictions are fully fungible, differently from the case of quantitative restrictions in which allowances are not fully fungible.

Another difference between quantitative restrictions and border tax on allowances transfer is that the implementation of border tax

gains peak when allowing 30\% domestic allowances to be imported from abroad. With tighter restrictions on allowances imports, importers gradually lose all gains from trading. Quemin and de Perthuis (2019) find that the scarcity rent exceeds the aggregate economic gains from trade when the number of transactions is limited under two-thirds of the trading amount under full linking. 
raise revenues for the corresponding jurisdiction authority, while a quantitative restriction generates a scarcity rent captured by importing or exporting entities.

As in the cases of full linking and quotas examined above, border taxes on allowances transfer are not expected to change the total amount of abatement activities across linked jurisdictions, though they will lead to a transfer of abatement activities between linked jurisdictions.

\section{- Exchange rates (or trading ratios)}

The economic and abatement implications of exchange rates change largely depending on the ratio. If the exchange rate ratio is set within the interval between one and the price ratio under no linking (hereafter indicated as "the effective interval"), cost-effectiveness and market liquidity are improved as compared to a no-linking scenario. Both peak when the exchange rate approaches one (the lower bound of the effective interval). Cost-effectiveness decreases monotonically at a non-linear rate within the effective interval and will be the lowest when the price ratio gets close to the upper bound of the effective interval, though it is still more cost effective than under autarky (Quemin and de Perthuis, 2019; Schneider et al., 2017). Outside the effective interval, cost-effectiveness turns out to be higher compared to the no linking scenario when the exchange rate is less than one, but lower when the exchange rate is larger than the price ratio under no linking.

Differently from quantitative restrictions or border taxes, that show no change in overall abatement compared to no linking, entities across two jurisdictions abate more in the case of exchange rates with respect to the no linking scenario. The abatement outcome peaks at some middle point within the effective interval. ${ }^{27}$ However, if the exchange rate is set outside the effective interval, total abatement decreases and is less than the amount under the no linking or full linking scenario.

In summary, only exchange rates within the effective interval guarantee both cost-effectiveness and increased abatement as expected outcome of linking. Exchange rates can serve as a multifunctional instrument in

\footnotetext{
${ }^{27}$ The overall abatement displays an inverted-U shape within the effective interval. For instance, Lazarus et al. (2015) investigate linkage between two jurisdictions assuming that the price ratio equals three under autarky, and find that the abatement peaks at a 1.74 exchange rate.
} 
pursuing different policy objectives. But approaching and maintaining the "best" exchange rates requires a balance of different policy objectives within and across linked jurisdictions and a high level of information symmetry among stakeholders.

\section{- Discount rate}

With discount rates, allowances trading between two ETSs will only be triggered when the market price ratio in case of no linkage exceeds the discount rate.

For example, imagine that the discount rate is set at $20 \%$ in both jurisdictions, namely, 1 imported allowance is worth 0.8 in each jurisdiction, and the price ratio is 1:0.9 (i.e. price equals 1 in jurisdiction $\mathrm{A}$ and 0.9 in jurisdiction B). In this case, regulated entities in the high-price jurisdiction (A) will not be willing to spend 0.9 to import one allowance from the low-price jurisdiction (B), as the latter is only worth 0.8 in the high-price jurisdiction (A). Entities in A will only import allowances from $\mathrm{B}$ if prices in $\mathrm{B}$ fall below 0.8 , that is, if the price differential rises above $20 \%$ (i.e. the discount rate).

When both jurisdictions set discount rates above one, the economic implications and the possible outcomes of a discount rate mechanism are similar to those examined under the case of exchange rates within the effective interval.

\section{Theoretical Aspects of Delinking}

Despite the rapidly growing literature on full and restricted linking, little attention has been devoted to delinking so far. However, as Pizer and Yates (2015) have pointed out, the way delinking is organized may affect price formation and abatement costs. Indeed, when permits can be banked to meet future targets, the mere speculation on whether the partners will terminate the linkage agreement at some point can alter the firms' intertemporal decisions, even if delinking never actually occurs. Therefore, as Mehling and Haites (2009) had previously argued, linking agreements should have at the outset a procedure for terminating the link that addresses the status and validity of banked permits.

To investigate this issue more in depth, Pizer and Yates (2015) examine a theoretical model that takes two possible delinking policies into account: one that differentiates banked permits by their origin, the 
other that treats banked permits the same. In the former case (what they call "asymmetric delinking") saved permits can only be used in the region for which they were originally issued, whereas in the latter case ("symmetric delinking") they can be used to cover emissions also in the linked region(s). Using a two-country two-period model, the authors show that different delinking rules may have very different market outcomes: asymmetric delinking increases aggregate abatement costs and creates price divergence across jurisdictions, whereas under symmetric delinking prices do not diverge and the increase in abatement costs is much lower. In particular, under asymmetric delinking the decision to terminate the joint programme may create price divergence well before delinking actually occurs.

The results emerging from the model suggest that any jurisdiction contemplating a linking agreement has to face a trade-off between uncertainty on the duration of the link and costs of delinking. On the one hand, introducing explicit delinking provisions may feed negative expectations on the capacity of the linking agreement to hold over time, generating uncertainty in the market operators on how long the linkage will last. On the other hand, ignoring the possibility of delinking and promising the partner "eternal love" (i.e. communicating strong commitment to a permanent link with the other jurisdiction) may turn out to be very costly if delinking occurs.

The possible role of delinking in affecting market outcomes is considered also by Heitzig and Kornek (2018). Using a game theoretical model of far-sighted coalition formation and allowing for reversible agreements (i.e. that can be terminated by any partner at any time), the authors show that the possibility to delink may actually reduce, somehow counterintuitively, the likelihood of delinking. Indeed, if partners are far-sighted agreements that could be terminated later are not signed in the first place, so that no delinking will actually occur at a later stage.

The authors examine linking with endogenous decisions on whether to coordinate caps. They find that if agents are sufficiently far-sighted, caps are coordinated immediately when markets are linked and delinking is allowed, then an efficient global coalition may emerge. The authors conclude that even if there are only few coordinated carbon markets at present, a first-best global cap-and-trade system might still emerge under the Paris Agreement. As the authors point out, however, 
these somehow optimistic results crucially depend on how far-sighted players are.

\section{Linking and Delinking in the Real World}

\section{The California-Québec Joint Cap-and-Trade Programme}

Despite the theoretical benefits of linking pointed out above, very few examples of linkage are actually available to test such benefits and support the conclusions of the ex-ante literature. The multi-faceted nature of linkage as well as the growing heterogeneity in ETS designs and governance frameworks pose, indeed, many challenges to prospective partners. The most prominent existing example of linking is the California-Québec joint cap-and-trade programme, which covers over 500 metric tons of $\mathrm{CO}_{2}$ equivalent $\left(\mathrm{MtCO}_{2} \mathrm{e}\right)$ emissions from about 626 entities.

California and Québec formally linked their ETSs on January 1, 2014. Their first joint auction was held in November 2014. All tradeable units (allowances and offsets) can be used both in California (hereafter CA) and Québec (hereafter QC) to meet compliance obligations by participating entities. Although the absolute emission level in CA is much higher than that in $\mathrm{QC}$, the per capita emission levels are relatively comparable. ${ }^{28} \mathrm{CA}$ has committed to reducing its emissions to the 1990 level by 2020 , and by at least $40 \%$ below the 1990 level by 2030 . The reduction targets of QC for the same periods of time were $20 \%$ below the 1990 level by 2020 , and $37.5 \%$ below the 1990 level by 2030. Comparing these targets suggests that QC had more ambitious reduction targets with respect to CA during the period until 2020, but the ambition targets have been subsequently aligned and are largely similar for the next decade. ${ }^{29}$ It is important to stress that only a fraction of the emissions reductions is to be achieved through each jurisdiction's capand-trade programme. For example, the cap-and-trade programme in

${ }^{28}$ The total GHG emissions in CA were 424 million metric tons of $\mathrm{CO}_{2}$ equivalent $\left(\mathrm{MtCO}_{2} \mathrm{e}\right)$ in 2017 (CARB, 2019), while they were $78 \mathrm{MtCO}_{2} \mathrm{e}$ in QC in 2017 (ECCC, 2019). Per capita GHG emissions in CA were 10.7 tonnes per person in 2017, while in $\mathrm{QC}$ they were 9.4 tonnes per person in the same year.

${ }^{29}$ Notice that CA achieved its 2020 emissions reduction goal already in 2018, while QC is likely to miss its 2020 goal: indeed, emissions in QC have dropped by only $9.3 \%$ compared to the 1990 level by 2017 (ECCC, 2019). 
CA is estimated to contribute to about $38 \%$ of CA's reduction target from 2021 to 2030 (CARB, 2017).

The cap-and-trade systems of CA and QC operate under guidelines of the Western Climate Initiative (WCI), a voluntary subnational intergovernmental organization initiated in 2007. As some authors have argued (e.g., Purdon et al., 2014), successful implementation of a linked programme in CA and QC might induce other partners to join in and could provide a blueprint for an eventual federal or even continental emissions trading market.

While the conditions under which these two ETSs operated were similar, several differences were needed to be assessed and solved in order to create a single market. ${ }^{30}$ A consultation committee was established to monitor the coordination of the programmes and report at least annually. ${ }^{31}$ In order to facilitate the harmonization process, CA and QC classified their cap-and-trade provisions into three categories (ICAP, 2015):

- Provisions that had to be identical: a "joint auction" of allowances is required and all transfers of allowances between programmes must take place within a "common registry";

- Provisions that had to produce similar outcomes but did not need to be identical: "monitoring, reporting and verification (MRV) process" - different requirements for verifiers, different monitoring timelines or reporting deadlines; and

- Provisions that could remain different: recognition of "offset credits" from a voluntary offset programme that started several years before the CA ETS, and recognition of "early action" credits to QC industry for reduction that took place prior to the implementation of the QC programme.

Both CA and QC have agreed to an auction floor price. The two jurisdictions decide their floors separately and the higher one is taken

${ }^{30} \mathrm{~A}$ comparison of the two systems from the legal and regulative perspectives (e.g., coverage, allocation, banking, and MRV) can be found in Vaiciulis (2015) and Purdon et al. (2014).

${ }^{31}$ For the highlights of the linking agreement, please refer to Linkage Readiness Report (CARB, 2013). 
as the floor in the joint auction based on the exchange rate reported the day before the auction. The minimum allowance price was set at $\$ 10$ USD in 2012 in CA and increases annually by $5 \%$, plus the rate of inflation. While $\mathrm{CA}$ and $\mathrm{QC}$ agreed on a floor price, a regulatory discrepancy between the two systems was unilaterally introduced on December 13, 2018 when the California Air Resources Board (CARB) approved the adoption of a price ceiling to prevent carbon price from rising without limit in California. It is too early to evaluate the possible effects of this unilateral decision; however, it might reinforce the already existing financial transfers from Québec to California. If this process were to continue, it might become a possible source of concern for the stability of the California-Québec linking agreement and the Québec government might have to take corrective actions in the future.

Taking the exchange rate into account, QC allowance prices were lower than the price in CA before their linking. The linkage of the two systems has enhanced market liquidity, especially for QC-based industries. After linking the QC market experienced a remarkable rise in the percentage of available allowances being sold, suggesting that the market is becoming more mature.

However, auction sales are always subject to uncertainty and volatility. There has been a sharp demand fall in the second quarterly auction of 2016 and again in February 2017. Much of the explanation for this reversal revolves around legal uncertainty regarding the future of the programme, as well as the allowance oversupply (Busch, 2017). Since May 2017, however, the auctions held experienced a remarkable recover in demand. Busch (2017) suggests that long-term auction demand tends to be strong, with a predicted $76 \%$ sale out of total supply through 2020 .

As for cost-effectiveness, there has been very little published research evaluating the joint programme as compared to the scenario without linking. Some ex-ante evaluations have tried to forecast and compare CA-QC market scenarios under linking and no linking (CARB, 2012; Purdon et al., 2014). Following Purdon et al. (2014), we can summarize the economic impact of linking as follows:

- Effect of linking on allowance prices

As previously stated, the 2020 emission reduction target has been more ambitious in QC than in CA. Moreover, QC industries generally offer 
fewer opportunities to reduce emissions than CA (Purdon et al., 2019, 2014). Therefore, the cost of complying with the reduction goal is considered to be higher in QC than in CA (CARB, 2012; Purdon et al., 2014).

Market prices have been almost steadily increasing since the first joint auction, and they have been well above price floor since May 2017. This seems to suggest that linkage is triggering allowance demand in the joint market. Prices after linking are mainly determined by the CA market due to its larger size (Purdon et al., 2014). As a consequence, the linkage with Québec is likely to affect the price of allowances in California much less than in Québec. Indeed, CARB (2012) predicted that the linkage with $\mathrm{QC}$ could cause the allowance price in $\mathrm{CA}$ to remain unchanged or increase only slightly as compared to a no linking scenario. As for QC, the allowance price under a joint programme was expected to be much lower than would have been the case under the no linking scenario. For QC to reach its 2020 emissions reduction target, economic models estimate that market prices would average 48-56 USD per $\mathrm{tCO}_{2} \mathrm{e}$ in the no-linking scenario, in contrast to an average 23-45 USD per $\mathrm{tCO}_{2} \mathrm{e}$ in the linking scenario (Purdon et al., 2019).

However, as Purdon et al. (2019) have pointed out, estimated average carbon prices obtained from ex-ante evaluations differ from carbon prices observed in the linked system so far (around 18 USD in 2019), which have remained much lower than anticipated by economic models. This observation has raised some concerns over the ability of the linked carbon markets to deliver the emission reduction targets set by $\mathrm{CA}$ and QC for 2030 (Purdon et al., 2019).

\section{- Effect of linking on economic growth}

Revenues are expected to flow into the CA economy as a result of regulated entities in $\mathrm{QC}$ seeking to reduce their compliance costs by purchasing Californian allowances. The potential inflow of revenues is expected to positively affect the CA economy, although by a limited amount $(0.04 \%)$ in terms of GDP growth (CARB, 2012). ${ }^{32}$

\footnotetext{
${ }^{32}$ For $\mathrm{CA}$, the slight rise in prices over unlinked prices is expected to increase the cost of reducing 14.4-18.3 million $\mathrm{tCO}_{2}$ e by about $\$ 13-56$ million. Nonetheless, inflows from QC would more than compensate for these additional costs and CA's net gain from trade are estimated to be around \$284-442 million (Purdon et al., 2014).
} 
The joint cap-and-trade programme is expected to allow QC to save up to $59 \%$ compliance costs, which would have been otherwise spent under a no linking scenario (CARB, 2012). Purdon et al. (2014) suggest that QC gains between $\$ 34$ and $\$ 110$ million from the saved compliance costs through linking. In summary, both $\mathrm{CA}$ and $\mathrm{QC}$ seem to gain from linking, though most of the benefits may accrue to CA.

Linking $\mathrm{CA}$ and $\mathrm{QC}$ can also provide administrative and institutional benefits through shared administrative infrastructure, procedures, and costs (Burtraw et al., 2013; Morehouse, 2017). In particular, Burtraw et al. (2013) suggest that the joint allowance auctions held by California and Québec significantly reduce management and transaction costs by providing a common set of rules and prices.

\section{Other Linking Experiences}

Beyond the California-Québec joint programme, other linking experiences can be identified in different world regions at every government level: cities, states, and supranational level. As to linking at the city level, Tokyo and the province of Saitama in Japan have been operating a joint carbon market since 2011, when the Saitama ETS was launched. The overall system covers about $100 \mathrm{MtCO}_{2}$ emissions (64.8 under the Tokyo ETS and 36.6 under the Saitama one) and 1,703 facilities (large buildings, factories, heat suppliers, and other facilities that consume large quantities of fossil fuels), about two-thirds of which are located in Tokyo and the remaining third in Saitama (ICAP, 2020).

As to the state level, the Regional Greenhouse Gas Initiative (RGGI) was the first mandatory GHG ETS in the United States. The system, which covers about $463.6 \mathrm{MtCO}_{2} \mathrm{e}$ emissions from 168 sources from the power sector, started operating in 2009 in 10 US north-eastern states on the basis of a Memorandum of Understanding signed by participating states in 2005. Each state initially established individual $\mathrm{CO}_{2}$ budget trading programmes and each one has its own statutory and/or regulatory authority. Participating states periodically review the ETS programme to evaluate its evolution and performance (ICAP, 2020). Other states could join RGGI in the near future, such as Virginia, which is about to establish an ETS and could enter RGGI by the end of 2020, and Pennsylvania, which is expected to develop a proposal for 
an ETS covering the power sector by July 2020 and could link to RGGI by 2022 (ICAP, 2020).

Finally, another linking example, in this case at the supranational level, concerns the EU ETS which has continued to expand to additional countries. Three EEA States (Norway, Iceland, and Liechtenstein) joined the EU ETS in 2007. More recently, Switzerland and the EU have reached an agreement on joining their own programmes. Unlike the other EEA States, where their ETSs became part of the EU ETS, Switzerland has maintained its own ETS and revised it since December 2011 so as to increase its similarity with the EU ETS and thus improve the linking prospects over time (Galdi et al., 2020). A linking agreement between Switzerland and the EU was signed in Bern on November 23, 2017, and subsequently approved by the Swiss Parliament on March 22, 2019. Finally, the agreement was ratified by both parties and became operational on January 1, 2020, thus concluding a long negotiation process which took almost a decade to be completed. ${ }^{33}$

Examples such as the EEA states joining the EU ETS and northeastern US states collaborating together to form the RGGI are sometimes not considered as real examples of linkage in the literature. These markets were established with a clear commitment to join existing ETS. While they might be based on separate (state or national) legislations, the schemes were operated under virtually identical rules and regulations. In these cases, linking essentially amounts to an extension of the scope of the set of linking partners. Given the harmonization of their design features, it was relatively easy for regulators from both sides to reach linking agreements. In the case of California-Québec as well as in the EU-Switzerland linking, instead, the schemes were set up as stand-alone mechanisms, and have worked independently for some time.

Another important linking experience at the European level concerns the linkage between the EU ETS and the Clean Development Mechanism $(\mathrm{CDM})$, which has been in place since the beginning of the EU ETS in 2005. This allowed companies to pay for offsets abroad through the CDM as a way of meeting their EU emissions quotas. In 2011, the EU introduced restrictions on the use of offset credits from the CDM

\footnotetext{
${ }^{33}$ Negotiations had started at the end of 2010, when the European Council authorised the European Commission on December 17, 2010 to open negotiations with the Swiss Confederation for a linking agreement.
} 
from specific project types due to the glut of allowances in the market. Prices of credits from such projects immediately diverged from those of European Union Allowances (EUAs) and of other CDM credits, given that they could no longer be sold in the EU market. Holders of such credits, therefore, flooded the New Zealand market, as New Zealand had not yet introduced the same restriction. This supply shift had the effect of lowering the price of New Zealand allowances (Diaz-Rainey and Tulloch, 2018). Soon, thereafter, the New Zealand government introduced its own restriction on the same CDM credit types. ${ }^{34}$ In this case, therefore, both jurisdictions switched from full linking to CDM to restricted linking schemes.

Beyond the limit to the use of the Kyoto offsets within the EU ETS, another driver of the price spread between EUAs and CERs was uncertainty on the future expected supply and demand of offsets (Hintermann and Gronwald, 2019). Indeed, the generation and verification of emission offsets is a lengthy and complicated process (Trotignon and Leguet, 2009). This generated uncertainty on the expected total supply of offsets at a certain date. Moreover, the extent to which Annex B countries needed to rely on offsets to achieve their targets under the Kyoto Protocol was also uncertain, thus generating uncertainty also on the demand of offsets (Hintermann and Gronwald, 2019).

In general, it can be claimed that the linkage between the EU ETS and the Kyoto Flexible Mechanisms like the CDM has had mixed results. On the one hand, the linkage has spread the carbon price signal to countries and sectors beyond those subject to the EU ETS. On the other hand, the inflow of international credits has had a negative impact on the EUA prices and on the credibility of the overall system due to some of the projects underlying the credits. The Paris Agreement's Cooperative Approaches build upon the experience of the Kyoto Protocol's Flexible Mechanisms with the intent to help Parties increase their ambition in reducing emissions (Schneider et al., 2016). Indeed, as argued by

\footnotetext{
${ }^{34}$ In December 2013 the New Zealand government announced its withdraw from the second commitment period of the Kyoto protocol, taking effect in May 2015. However, the long duration between the announcement (December 2013) and the effectiveness of the delinking from the Kyoto Protocol (May 2015) created an incentive to importing and surrendering cheap Kyoto units and banking domestic allowances for future periods, which may have depressed prices and undermined the effectiveness of the ETS (Kerr and Ormsby, 2016).
} 
Marcu (2016), the final goal of Article 6 of the Paris Agreement (PA) is to lead to an improved Kyoto-type CDM allowing for international emissions trading. In particular, by introducing provisions for Parties to cooperate through internationally transferred mitigation outcomes (ITMOs), Articles 6.2 and 6.3 pave the way to linking among ETSs. Article 6 remains the object of a heated debate on how to actually implement its underlying mechanisms (Cames et al., 2016; Olsen et al., 2018). However, the PA clearly promotes international climate cooperation in general, and carbon market cooperation in particular, as a way to lower the costs of meeting their own NDCs and thus increase their ambition in mitigation.

\section{From Marriages to Divorces: Past (and Future?) Delinking Examples}

In the previous sections we described the most important linking experiences up to now. However, as real-life marriages, some union did not have a happy ending or look at risk right now. In this section we briefly describe a few cases which ended up with delinking or might do so in the future.

Given the success of the California-Québec cap-and-trade system, Ontario decided to join the programme thus giving origin to a multilateral ETS. The linkage was expected to significantly reduce compliance costs for regulated entities in Ontario (Sawyer, 2015), as they could use the additional abatement opportunities in the other WCI jurisdictions, particularly in California. For Ontario, the Gross Domestic Product (GDP) loss to achieve the given reduction target was estimated to be much lower (at least eight times) under the linked system than in an isolated Ontario market (Sawyer et al., 2016).

Despite this positive outlook, the "marriage" between Ontario and the California-Québec joint programme did not last long, and Ontario soon delinked from the CA-QC market. The Ontario's cap-and-trade programme, which had been operating since 2016, joined the CaliforniaQuébec market as of January 1, 2018, under a harmonization and integration agreement announced in September 2017. But with the newly elected Ontario government, the cap-and-trade programme was cancelled in July 2018, and all trading of emission allowances were prohibited. 
This sudden change of political direction resembles other examples of delinking which occurred elsewhere. At the end of 2011, for instance, New Jersey - one of the founding members of RGGI - ceased its participation in the scheme which was considered to be ineffective in emissions reduction. However, following the election of a new governor, New Jersey subsequently re-examined the decision retracing its steps: after various vicissitudes, New Jersey eventually adopted an ETS legislation in 2019 and rejoined RGGI at the beginning of 2020. This case shows that, as it happens in some troubled love story in which partners repeatedly get together and break up, also the decisions to link and delink can be subject to periodical revisions, although this kind of uncertainty on the future prospects of the linkage is generally undesirable for market operators' decisions.

Another delinking example due to a sudden political change is the one involving Europe and Australia. Prior to the outcome of the Australian national election in September 2013, the European Commission and the Australian government had announced their intention to link their ETS programmes. Before the election, the ruling government coalition in Australia implemented a Carbon Pricing Programme (CPP) that would have involved a carbon market starting in 2015. The first stage of linking was planned to start in July 2015 with a "one-way" (unilateral) link, whereby covered entities in Australia would have been able to use European Union Allowances to fulfil up to $50 \%$ of their compliance obligations. The linkage was expected to become "two-way" (bilateral) at the beginning of July 2018, when EU entities would have been able to use Australian Emission Units (AEUs) to fulfil their liabilities. However, the linking proposal caused concerns regarding emission reduction ambition and cross-border financial transfers. Eventually, the linking proposal was abandoned since the party that won the 2013 elections and the new Australian government resulting from the elections decided to cancel the programme and repeal its ETS legislation. Strictly speaking, the EUAustralian experience is not a real case of delinking, since linking was not yet in place. To use our initial metaphor, it could be said that Australia broke off the engagement with Europe rather than actually divorced Europe. Nevertheless, this case shows how long and advanced negotiations can be rapidly swept away by domestic electoral results in one of the partners. This calls for a cautious design of the linking schemes including, for instance, clear delinking provisions at the outset, as discussed above. 
Beyond the examples mentioned above, another possible case of delinking seems to emerge at the horizon. Following Brexit, the UK and the EU started a long negotiation process which concerns also the future participation of the UK to the EU ETS. At the moment of writing the outcome of the UK-EU negotiations on the EU ETS appears still rather uncertain and open to all possible scenarios, including the exit from the EU ETS and launch of a UK carbon market once the country exits the post-Brexit transitional period at the end of 2020 (Carbon Pulse, 2019). The UK ETS could then link back with the EU ETS following the precedent of the EU-Swiss link. A few steps had been jointly taken by the EU and the UK in the early phases after the Brexit vote. In particular, in November 2017 UK and EU agreed that UK emitters had to face earlier compliance deadlines in 2019 and had to surrender carbon units before the scheduled Brexit date, which eventually took place on January 31, 2020. In March 2018, negotiators reached a deal on a transition period to the end of 2020, during which the UK no longer participates in EU decision-making processes but is still subject to the single market rules (Carbon Pulse, 2018).

Several studies have recently tried to predict the possible consequences of Brexit from the EU ETS on both the EU and the UK (e.g., Babonneau et al., 2018; Borghesi and Flori, 2019; Tol, 2018). The studies generally conclude that delinking would be more detrimental for the UK, while it might have different consequences on different countries within the EU. ${ }^{35}$

In particular, Tol (2018) finds that a UK departure from the EU ETS would have limited consequences on the remaining 27 member states, while its impact being much larger for the UK in terms of increased compliance costs with its climate policy targets, transition costs to replace the EU ETS and possible business loss as carbon trade leaves the UK.

Babonneau et al. (2018) also find that Brexit might have a significant negative impact on the UK's climate policy cost. In a hard Brexit scenario (assuming the UK has no access to the EU ETS and is not

\footnotetext{
${ }^{35}$ Other contributions (Carvalho and Fankhauser, 2017; Dupont and Moore, 2019) analyse the implications of Brexit in the broad perspective of global climate governance and suggest that - given the role of the UK in shaping the European action on climate change in the past - the EU climate agenda might slow down after Brexit due to the loss of the UK as an important advocate.
} 
involved in the Effort Sharing Decision rules), the UK's discounted welfare cost would be equal to $1.30 \%$ of its discounted household consumption. The remaining EU-27 countries would also experience some costs since additional abatement would be needed to compensate for the non-participation of the UK, but the analysis suggests that the EU welfare costs would be much lower ( 8 billion $€$ for EU-27 versus 15 billion $€$ for the UK in 2030).

In the alternative scenario in which the UK is assumed to participate to the EU ETS with a third-country status similar to Norway and Liechtenstein, Babonneau et al. (2018) estimate that the welfare cost for the UK would be reduced by around $20 \%$ (from $1.30 \%$ to $1.06 \%$ of its discounted household consumption) since access to emission credits would lower costs compared with domestic abatement. The EU-27 as a whole would also be better off if the UK keeps participating in the EU ETS with respect to a hard Brexit scenario. In fact, the UK is a net buyer of allowances, therefore its participation in the EU ETS generates financial entries that can be used by the EU for redistribution purposes across its Member States. However, results vary greatly for the remaining EU Member States depending on their positions on the EU ETS (whether they are net buyer or net seller of allowances)..$^{36}$

Finally, using network theory analysis, Borghesi and Flori (2019) investigate the possible impact of Brexit on the structure of the EU ETS market. The UK has always played a pivotal role in the EU ETS as a central hub for the exchange of allowances in the market (Borghesi and Flori, 2018), therefore, the UK departure could deeply modify the number and directions of such exchanges as well as the centrality of the other countries in the market. To get a deeper understanding on this issue, the authors examine a few different scenarios deriving from a possible reallocation of the transactions that are currently involving UK partners. Results suggest that a hard Brexit would change the structure of the EU ETS network from a star-like system (with UK at the centre of the star and its partners surrounding it) to a core-periphery structure in which a set of core countries (France, Germany, Denmark,

\footnotetext{
${ }^{36}$ Notice that all the calculations in Babonneau et al. (2018) are conducted using 2016 prices. The sharp rise in the EUA prices since 2018 might significantly influence the results emerging for single countries under this scenario.
} 
Netherlands, partly Italy) become more central in the network while the others remain at the periphery of the system.

Given the present political uncertainties, it is too early to conclude whether and how the UK will leave the EU ETS and what its consequences might be. However, a UK exit from the EU ETS would represent an unprecedented case of delinking for the key role of the partner involved, both in terms of its emissions (the UK being the second biggest emitters in the EU ETS) and of its centrality in the allowances exchange.

\section{Concluding Remarks on Linking (and Marriages)}

Linking ETSs has attracted much attention in the last years as a possible bottom-up way of building coalitions of countries who are more active in using carbon pricing mechanisms. Several theoretical studies have investigated how linking can be implemented in practice. Existing studies suggest that linkage can take different forms. Choosing the appropriate approach will depend on specific linking occasions, emissions reduction expectations and policy goals. In general, full linking provides the largest economic benefits, yet requires considerable harmonization and compromise between participants (Borghesi et al., 2016). A number of recent studies have explored restricted linkage as a feasible alternative to full linking. Through restricted linking approaches, jurisdictions are expected to capture some of the benefits associated with full linking subjects to specific conditions. Restricted linking can be a suitable route on the way towards full linking. It can be seen as progressive steps of integration in line with the idea of "linking by degrees" proposed by Burtraw et al. (2013); a temporary solution that allows to pursue a cautious approach in linking and can limit the propagation of undesirable problems originating in the partner jurisdiction. Within restricted linking, the preferable approach among the existing alternatives depends on the regulator's priorities. For instance, if the government's priority is to raise revenues (e.g., for redistribution purposes) then border taxes on allowances transfers should be used; if the regulator wants to keep under control the volume of allowances being transferred to avoid large financial transfers across jurisdictions then quantitative restrictions appear the appropriate way to proceed. If the government wants to account for different stringency 
levels in the linked jurisdictions then exchange rates (or discount rates, that are their unilateral version) could be used. In general, therefore, there is not a one-size-fits-all solution but the best way to proceed depends on the features and goals of the jurisdictions involved. Yet, all the linking approaches face certain challenges.

Indeed, as a marriage between individuals, linking between jurisdictions can have pros and cons. Linking has a number of potential advantages for participant jurisdictions in economic, regulatory, and political terms. In economic terms because it increases compliance opportunities and the liquidity of the market; in regulatory terms because linking allows to share information, learn from each other, and spread the best practices among linked jurisdictions; in political terms because linking can spur international cooperation on climate change, providing a bottom-up solution that can overcome the difficulties encountered by environmental multilateralism.

However, enjoying the benefits of linking comes at some costs. In the first place, linking implies a partial loss of sovereignty for the Parties: like in a marriage both individuals have to give up some of the freedom they had as single for the benefit of the family, similarly when linking jurisdictions give up part of their control over their own ETS which is now jointly ruled together with the partner jurisdiction. This can be a challenge since ETSs are generally part of a wider domestic climate policy package. In the second place, linking with a jurisdiction which sets unclear rules and/or does not enforce them properly may cause a loss of accountability and transparency. As in a marriage the financial situation may be damaged and become unclear if one of the two partners has little control over his/her own expenditures, similarly the accountability of linked regimes may become difficult to manage and their transparency reduced if rules and conditions are not properly set. In the third place, linking with the wrong partner may undermine the credibility of one's own ETS, just like what may happen in a marriage to an individual if his/her partner does not respect payment deadlines or does not return a loan. In case of linking, a credibility loss may spread negative effects on prices and behaviors from one ETS to the other, making one's ETS more vulnerable to the partner's mistakes. Finally, linking will alter carbon prices and induce a financial transfer between jurisdictions, which can be particularly challenging for authorities in the allowance importing jurisdiction. 
Beyond the existence of costs and benefits from getting together, linking between jurisdictions resembles marriages in other respects. Indeed, like marriages (at least in those countries where divorce is allowed), linking is a reversible (though costly) decision. Though two individuals initially promise each other eternal love, the latter can finish at some point and each one can take his/her own way. Metaphorically speaking (replacing individuals with jurisdictions and love with much less exciting legal agreements), this seems to happen with linking as well. ${ }^{37}$ The cases of delinking described above should induce a jurisdiction to proceed with much caution when choosing its own partner or at least be prepared to the possible exit of the counterpart from the linking agreement in the future. The real-world examples discussed in this paper show how difficult and unstable linking can be.

Despite the similarities one can find between linking and marriages, there remains a crucial difference. Indeed, differently from marriage, which involves two individuals, linking can involve multiple partners: extending the linkage to additional partners can actually be even more beneficial since it increases the size and liquidity of the market.

If we look at the real world, however, we observe very little linking so far and only few attempts at extending an existing linking agreement to an additional partner (which ended up with the delinking of Ontario in the $\mathrm{CA}-\mathrm{QC}$ case, or which is actually an attempt to rejoin RGGI in the case of New Jersey). Why is that the case?

In our view, one can identify at least three possible explanations. First, as shown by the real-world examples discussed before (e.g., the EU-Switzerland case), linking requires detailed negotiations between jurisdictions, which takes time. Since the diffusion of ETSs is a still relatively new phenomenon, therefore, it is probably too early to observe linking agreements operating in practice. A second potential explanation is that the disadvantages of linking are actually higher than its advantages, or at least they are perceived to be so. A third possible

\footnotetext{
${ }^{37}$ Actually, some marriages are not initially motivated by love but rather by underlying strategic interests, such as enjoying high living standards and fame by marrying a wealthy and famous spouse, establishing or reinforcing family connections (e.g., among royal houses or families leading big industrial groups) etcldots Mutatis mutandis, strategic reasons (e.g., creating or entering a climate club, establishing or reinforcing trade connections with the other jurisdiction etc..) may play a key role in the linking decision as well.
} 
reason is that, although the overall benefits can be higher than the related costs for the joint jurisdictions taken together, benefits may be unevenly distributed. This calls for a new research line that may deepen in the future our understanding of the distribution of the potential costs and benefits of linking both within and across different partners. Indeed, if we exclude some interesting contributions on bilateral and multilateral linking (Doda et al., 2017; Doda and Taschini, 2017a), the distribution of the benefits from linking and the role of inequality as a possible obstacle to linking have been partially ignored so far.

Linking ETSs represents an interesting opportunity to capture the potential benefits of carbon markets. However, further theoretical studies and more empirical evidence on the costs and benefits of linking are currently needed to fully exploit the potentialities of linking and implement them in reality. We believe that linking should be further pursued in the future but this should be done with much caution, as Doda and Taschini (2017b) have argued. In particular, in our view, it is important to avoid a priori ideological positions in favour or against linking and to properly evaluate when linking can be actually beneficial to the partners, sufficiently stable in the long run, and really effective in reducing emissions for the environment.

\section{References}

Antoniou, F., P. Hatzipanayotou, and P. Koundouri (2012), "Tradable Permits vs Ecological Dumping when Governments Act Noncooperatively", Oxford Economic Papers, 66(1), 188-208.

Babiker, M., J. Reilly, and L. Viguier (2004), "Is International Emissions Trading Always Beneficial?", The Energy Journal, 33-56.

Babonneau, F., A. Haurie, and M. Vielle (2018), "Welfare Implications of EU Effort Sharing Decision and Possible Impact of a Hard Brexit", Energy Economics, 74(C), 470-89.

Baron, R. and S. Bygrave (2002), Towards International Emissions Trading: Design Implications for Linkages, OECD Information Paper 5 .

Barrett, S. (1994), "Self-enforcing International Environmental Agreements", Oxford Economic Papers, 46, 878-94. 
Böhringer, C., B. Dijkstra, and K. E. Rosendahl (2014), "Sectoral and Regional Expansion of Emissions Trading", Resource and Energy Economics, 37, 201-25.

Bohringer, C., K. E. Rosendahl, and J. Schneider (2018), "Unilateral Emission Pricing and OPEC's Behaviour", Strategic Behavior and the Environment, 7(3-4), 225-80.

Borghesi, S. and A. Flori (2018), "EU ETS Facets in the Net: Structure and Evolution of the EU ETS Network", Energy Economics, 75, 602-35.

Borghesi, S. and A. Flori (2019), "With or without You: A Pre-Brexit Network Analysis of the EU ETS", PLoS One, 1-17, doi.org/10. 1371/journal.pone.0221587.

Borghesi, S., M. Montini, and A. Barreca (2016), The European Emission Trading System and Its Followers: Comparative Analysis and Linking Perspectives, Springer: Berlin, Germany.

Bramley, M., P. Partington, and D. Sawyer (2009), Linking National Cap-and-Trade Systems in North America. The Pembina Institute and the International Institute for Sustainable Development, Clean Energy and Climate Action.

Burtraw, D., K. L. Palmer, C. Munnings, P. Weber, and M. Woerman (2013), "Linking by Degrees: Incremental Alignment of Cap-andTrade Markets", RFF Working Paper 13-04.

Busch, C. (2017), Recalibrating California's Cap-and-Trade Program to Account for Oversupply: An Original Quantitative Analysis and Policy Recommendations, Energy Innovation Policy and Technology, LLC.

Caillaud, B. and G. Demange (2017), "Joint Design of Emission Tax and Trading Systems", Annals of Economics and Statistics, 127, 163-201.

Cames, M., S. Healy, D. Tänzler, L. Li, J. Melnikova, C. Warnecke, and M. Kurdziel (2016), "International Market Mechanisms after Paris", Discussion Paper. Berlin: DEHSt/UBA. https://www.adelphi.de/ en/publication/international-market-mechanisms-after-paris.

CARB (2012), Proposed Amendments to the California Cap on Greenhouse Gas Emissions and Market-Based Compliance Mechanisms to Allow for the Use of Compliance Instruments Issued by linked jurisdictions, California Air Resources Board, Sacramento, https: //www.arb.ca.gov/regact/2012/capandtrade12/isormainfinal.pdf. 
CARB (2013), Linkage Readiness Report, California Air Resources Board, Sacramento, https://www.arb.ca.gov/cc/capandtrade/ linkage/arb_linkage_readiness_report.pdf.

CARB (2017), "California's 2017 Climate Change Scoping Plan", California Air Resources Board. https://ww3.arb.ca.gov/cc/scopingplan/ scoping_plan_2017.pdf.

CARB (2019), California Greenhouse Gas Emissions for 2000 to 2017. Trends of Emissions and Other Indicators, California Air Resources Board, Sacramento. https://ww3.arb.ca.gov/cc/inventory/pubs/ reports/2000_2017/ghg_inventory_trends_00-17.pdf.

Carbon Pulse (2018), "EU, UK Reach Deal on Transition Period to the End of 2020", Tech. Rep. Published on March 19, 2018. https: //carbon-pulse.com $449217 /$.

Carbon Pulse (2019), “It Is happening”: UK Carbon Market Remains on Track for Jan. 2021 Launch, Says Govt Official", Published on March 3, 2019. https://earbon-pulse.com/93417/.

Carbone, J. C., C. Helm, and T. F. Rutherford (2009), "The Case for International Emission Trade in the Absence of Cooperative Climate Policy", Journal of Environmental Economics and Management, 58(3), 266-80.

Carraro, C. and D. Siniscalco (1993), "Strategies for the International Protection of the Environment", Journal of Public Economics, 52(3), 309-28.

Carvalho, M. and S. Fankhauser (2017), "With or without You? Why the European Union's Climate Targets Will Be Harder to Meet PostBrexit. LSE Brexit", http://eprints.lse.ac.uk/72891/1/blogs.lse.ac. uk-With\%20or\%20without\%20you\%20Why\%20the\%20European\% 20Unions $\% 20$ climate $\% 20$ targets $\% 20$ will $\% 20$ be $\% 20$ harder $\% 20$ to $\%$ 20meet\%20post-Brexit.pdf.

CCI (2020), Annual Report to the Legislature on California Climate Investments Using Cap-and-Trade Auction Proceeds, California Climate Investments. https://ww3.arb.ca.gov/cc/capandtrade/ auctionproceeds/2020_cci_annual_report.pdf.

Chung, R. K. (2007), "A CER Discounting Scheme Could Save Climate Change Regime after 2012", Climate Policy, 7(2), 171-6.

Dellink, R., M. Finus, and N. Olieman (2008), "The Stability Likelihood of an International Climate Agreement", Environmental and Resource Economics, 39(4), 357-77. 
Diaz-Rainey, I. and D. J. Tulloch (2018), "Carbon Pricing and System Linking: Lessons from the New Zealand Emissions Trading Scheme", Energy Economics, 73, 66-79.

Dijkstra, B. R., E. Manderson, and T. Y. Lee (2011), "Extending the Sectoral Coverage of an International Emission Trading Scheme", Environmental and Resource Economics, 50(2), 243-66.

Doda, B., S. Quemin, and L. Taschini (2017), "A Theory of Gains from Trade in Multilaterally Linked ETSs", GRI Working Papers 275, Grantham Research Institute on Climate Change and the Environment, London School of Economics.

Doda, B., S. Quemin, and L. Taschini (2018), Linking Permit Markets Multilaterally, ESRC Centre for Climate Change Economics and Policy London.

Doda, B. and L. Taschini (2017a), "Carbon Dating: When Is It Beneficial to Link ETSs?", Journal of the Association of Environmental and Resource Economists, 4(3), 701-30.

Doda, B. and L. Taschini (2017b), "Carbon Markets: Link with Caution", Nature, 544, 297, (20 April 2017).

Dupont, C. and B. Moore (2019), "Brexit and the EU in Global Climate Governance", Politics and Governance, 7(3), 51-61, URL: https: //biblio.ugent.be/publication/8628468/file/8628471.

ECCC (2019), "National Inventory Report 1990-2017: Greenhouse Gas Sources and Sinks in Canada: Executive Summary", Environment and Climate Change Canada. http://publications.gc.ca/collections/ collection_2019/eccc/En81-4-1-2017-eng.pdf.

Edenhofer, O., C. Flachsland, and R. Marschinski (2007), Towards a Global $\mathrm{CO}_{2}$ Market - An Economic Analysis, Potsdam Institute for Climate Impact Research.

Ellerman, A. D. and I. S. Wing (2000), "Supplementarity: An Invitation to Monopsony?", The Energy Journal, 29-59.

Erickson, P., M. Lazarus, and R. Spalding-Fecher (2014), "Net climate Change Mitigation of the Clean Development Mechanism", Energy Policy, 72, 146-54.

European Commission (2019), Commission Organises International Carbon Market Workshop in Florence, Italy, Climate Action News 22/3/2019, Brussels. URL: https://ec.europa.eu/clima/news/ commission - organises - international - carbon - market - workshop florence-italy_en. 
Eyckmans, J. and S. Kverndokk (2010), "Moral Concerns on Tradable Pollution Permits in International Environmental Agreements", Ecological Economics, 69(9), 1814-23.

Fell, H., E. Moore, and R. D. Morgenstern (2011), "Cost Containment under Cap and Trade: A Review of the Literature", International Review of Environmental and Resource Economics, 5(4), 285-307.

Fershtman, C. and A. de Zeeuw (2013), "Possible Inefficiencies in a Duopoly Trading Emission Permits", Strategic Behavior and the Environment, 3(4), 279-303.

Finus (2008), "Game Theoretic Research on the Design of International Environmental Agreements: Insights, Critical Remarks, and Future Challenges", International Review of Environmental and Resource Economics, 2(1), 29-67.

Flachsland, C., R. Marschinski, and O. Edenhofer (2009a), "Global Trading versus Linking: Architectures for International Emissions Trading", Energy Policy, 37(5), 1637-47.

Flachsland, C., R. Marschinski, and O. Edenhofer (2009b), "To Link or not to Link: Benefits and Disadvantages of Linking Cap-and-Trade Systems", Climate Policy, 9(4), 358-72.

Fuss, S., C. Flachsland, N. Koch, U. Kornek, B. Knopf, and O. Edenhofer (2018), "A Framework for Assessing the Performance of Capand-Trade Systems: Insights from the European Emissions Trading System", Review of Environmental Economics and Policy, 12(2), 220-41.

Füssler, J. and M. Herren (2015), Design Options for an International Carbon Asset Reserve for the World, Networked Carbon Markets, World Bank Group.

Füssler, J., A. Wunderlich, and L. Taschini (2016), International Carbon Asset Reserve. Prototyping for Instruments Reducing Risks and Linking Carbon Markets, Zurich, INFRAS.

Galdi, G., S. Verde, I. Alloisio, S. Borghesi, J. Füssler, T. Jamieson, B. Schäppi, E. Wimberger, and L. Zhou (2020), Informing the Carbon Market Policy Dialogue: The Emissions Trading Systems at a Glance, Florence School of Regulation, European University Institute, Florence.

Gersbach, H. and R. Winkler (2011), "International Emission Permit Markets with Refunding", European Economic Review, 55(6), 75973 . 
Godal, O. and B. Holtsmark (2011), "Permit Trading: Merely an Efficiency - Neutral Redistribution away from Climate - Change Victims?", The Scandinavian Journal of Economics, 113(4), 784-97. Greaker, M. and C. Hagem (2014), "Strategic Investment in Climate Friendly Technologies: The Impact of Global Emissions Trading", Environmental and Resource Economics, 59(1), 65-85.

Green, J. F. (2017), "Don’t Link Carbon Markets", Nature, 543(7646), 484-6.

Green, J. F., T. Sterner, and G. Wagner (2014), "A Balance of BottomUp and Top-Down in Linking Climate Policies", Nature Climate Change, 4, 1064-7.

Habla, W. and R. Winkler (2018), "Strategic Delegation and International Permit Markets: Why Linking May Fail", Journal of Environmental Economics and Management, 92, 244-50.

Heindl, P., P. Wood, and F. Jotzo (2014), "Combining International Cap-and-Trade with National Carbon Taxes", CCEP Working Paper 1418, Australian National University.

Heitzig, J. (2013), Bottom up Strategic Linking of Carbon Markets: Which Climate Coalitions Would Farsighted Players Form?, Nota di Lavoro 48.2013.

Heitzig, J. and U. Kornek (2018), "Bottom-up Linking of Carbon Markets Under Far-sighted Cap Coordination and Reversibility", Nature Climate Change, 8(3), 204-9.

Helm, C. (2003), "International Emissions Trading with Endogenous Allowance Choices", Journal of Public Economics, (87), 2732-47.

Helm, C. and S. Pichler (2015), "Climate Policy with Technology Transfers and Permit Trading", Environmental and Resource Economics, $60(1), 37-54$.

Hintermann, B. and M. Gronwald (2019), "Linking with Uncertainty: The Relationship between EU ETS Pollution Permits and Kyoto Offsets", Environmental and Resource Economics, 1-24.

Hoel, M. (1992), "International Environment Conventions: The Case of Uniform Reductions of Emissions", Environmental and Resource Economics, 2(2), 141-59.

Holtsmark, B. and D. E. Sommervoll (2012), "International Emissions Trading: Good or Bad?", Economics Letters, 117(1), 362-4. 
Holtsmark, K. and K. Midttømme (2019), "The Dynamics of Linking Permit Markets", CESifo Working Papers, ISSN 2364-1428, Munich, Germany.

ICAP (2015), Emissions Trading Worldwide, Status Report 2015. Berlin: International Carbon Action Partnership.

ICAP (2018), Emissions Trading Worldwide, Status Report 2018. Berlin: International Carbon Action Partnership.

ICAP (2020), Emissions Trading Worldwide, Status Report 2020. Berlin: International Carbon Action Partnership.

IETA (2006), Linking the EU ETS with Emerging Emissions Trading Schemes, 1-13, International Emissions Trading Association Washington, D.C.

Jakob, M., K. Lessmann, and T. Wildgrube (2014), "The Role of Emissions Trading and Permit Allocation in International Climate Agreements with Asymmetric Countries", Strategic Behavior and the Environment, 4(4), 361-92.

Kerr, S. and J. Ormsby (2016), "The New Zealand Emissions Trading Scheme De-link from Kyoto: Impacts on Banking and Prices. Motu Economic and Public Policy Research, Working Paper 16-13", https: //core.ac.uk/download/pdf/51343521.pdf.

Kersting, J. (2018), "Stability of Global Climate Cooperation under Uncertainty", Strategic Behavior and the Environment, 7(3-4), 35196.

Lapan, H. E. and S. Sikdar (2019), "Is Trade in Permits Good for the Environment?", Environmental and Resource Economics, 72(2), $501-10$.

Lazarus, M., L. Schneider, C. Lee, and H. van Asselt (2015), Options and Issues for Restricted Linking of Emissions Trading Systems, International Carbon Action Partnership.

Liu, X. (2010), "Extracting the Resource Rent from the CDM Projects: Can the Chinese Government Do Better?", Energy Policy, 38(2), 1004-9.

Marcu, A. (2015), Mitigation Value, Networked Carbon Markets and the Paris Climate Change Agreement, World Bank Group. 
Marcu, A. (2016), "Carbon Market Provisions in the Paris Agreement (Article 6)", CEPS Research Paper, Centre for European Policy Studies. Brussels https://www.ceps.eu/system/files/SR\%20No\%20128\% 20ACM \% 20Post \% 20COP21\% 20Analysis \% 20of\% 20Article \% 206. pdf.

Marschinski, R., C. Flachsland, and M. Jakob (2012), "Sectoral Linking of Carbon Markets: A Trade-Theory Analysis", Resource and Energy Economics, 34(4), 585-606.

Mehling, M. and B. Görlach (2016), "Multilateral Linking of Emissions Trading Systems", MIT Center for Energy and Environmental Policy Research. http://ceepr.mit.edu/files/papers/16-009.pdf.

Mehling, M. and E. Haites (2009), "Mechanisms for Linking Emissions Trading Schemes", Climate Policy, 9, 169-84.

Morehouse, E. (2017), Western Climate Initiative Expands: Ontario to Join California-Québec Carbon Market, EDF Talks Global Climate. Oliveira, T. D., A. C. Gurgel, and S. Tonry (2019), "International Market Mechanisms under the Paris Agreement: A Cooperation between Brazil and Europe", Energy Policy, 129, 397-409.

Olsen, K. H., C. Arens, and F. Mersmann (2018), "Learning from CDM SD Tool Experience for Article 6.4 in the Paris Agreement", Climate Policy, 18(4), 383-95.

Pizer, W. A. and A. J. Yates (2015), "Terminating Links between Emission Trading Programs", Journal of Environmental Economics and Management, 71, 142-59.

Purdon, M., G. Giuliano, J. Witcover, C. Murphy, S. Ziaja, C. Kaiser, M. Winfield, C. Sèguin, J. Papy, K. Sang-o, L. C. Coderre, M. Goulet, and L. Fulton (2019), "Climate and Transportation Policy Sequencing in California and Quebec", JCCTRP Working Paper Series 2019-2, Université du Québec à Montréal. https://jcctrp.org/ wp-content/uploads /2019/10/JCCTRP_Working-Paper-20192_17Oct2019.pdf.

Purdon, M., D. Houle, and E. Lachapelle (2014), The Political Economy of California and Québec's Cap-and-Trade Systems, Sustainable Prosperity, University of Ottawa.

Qi, T. and Y. Weng (2016), "Economic Impacts of an International Carbon Market in Achieving the INDC Targets", Energy, 109, 88693. 
Quemin, S. and C. de Perthuis (2019), "Transitional Restricted Linkage between Emissions Trading Schemes", Environmental and Resource Economics, 74, 1-32.

Ranson, M. and R. N. Stavins (2012), "Post-Durban Climate Policy Architecture Based on Linkage of Cap-and-Trade Systems", NBER No. w18140.

Rehdanz, K. and R. S. Tol (2005), "Unilateral Regulation of Bilateral Trade in Greenhouse Gas Emission Permits", Ecological Economics, 54(4), 397-416.

Santikarn, M., C. Kardish, J. Ackva, and C. Haug (2019), The Use of Auction Revenue from Emissions Trading Systems: Delivering Environmental, Economic, and Social Benefits, Berlin: International Carbon Action Partnership: https:/ / icapcarbonaction.com/en/ ?option $=$ com_attach\&task $=$ download\&id $=646$.

Sawyer, D. (2015), "The Cost and GHG implications of WCI Cap and Trade in Ontario", EnviroEconomics, https://www.enviroeconomics. org/single-post/2015/04/13/The-Cost-and-GHG-Implications- ofWCI-Cap-and-Trade-in-Ontario.

Sawyer, D., J. Peters, and S. Stiebert (2016), "Overview of Macroeconomic and Household Impacts of Ontario's Cap and Trade Program", EnviroEconomics, available at: https://drive.google.com/file/d/ 0B9FT5KrVwYmwZHV2M1RZbnZmUGM/view.

Schneider, L. (2009), "A Clean Development Mechanism with Global Atmospheric Benefits for a Post-2012 Climate Regime", International Environmental Agreements: Politics, Law and Economics, 9, 95-111. Schneider, L., D. Broekhoff, M. Cames, S. Healy, J. Fussler, and S. La Hoz Theuer (2016), Market Mechanisms in the Paris Agreement - Differences and Commonalities with Kyoto Mechanisms, German Emissions Trading Authority (DEHSt), German Environment Agency, Berlin.

Schneider, L., M. Lazarus, C. Lee, and H. van Asselt (2017), "Restricted Linking of Emissions Trading Systems: Options, Benefits, and Challenges", International Environmental Agreements: Politics, Law and Economics, 1-16.

Tol, R. S. (2018), "Leaving an Emissions Trading Scheme: Implications for the United Kingdom and the European Union", Review of Environmental Economics and Policy, 12(1), 183-9. 
Trotignon, R. and B. Leguet (2009), "How many CERs by 2013?", Mission Climat Working Paper Nr. 2009-5.

Vaiciulis, R. (2015), "Linking Emissions Trading Schemes: Analysis and Recommendations for EU-Australia and Québec-California Linkages, CIRL Occasional Paper No. 50".

Warnecke, C., S. Wartmann, N. Höhne, and K. Blok (2014), "Beyond Pure Offsetting: Assessing Options to Generate Net-MitigationEffects in Carbon Market Mechanisms", Energy Policy, 68, 41322 .

Weitzman, M. (2019), "For International Cap-and-Trade in Carbon Permits, Price Stabilization Introduces Secondary Free-Rider-Type Problems", Environmental and Resource Economics, 74, 939-42.

Wood, P., P. Heindl, F. Jotzo, and A. Loschel (2013), "Linking Price and Quantity Pollution Controls under Uncertainty", ZEW discussion paper 13-025.

Zaman, P. and A. Hedley (2016), "Networked Carbon Markets: The Regulatory Framework to Support Carbon Market Linkage - A Concept Paper", World Bank, Washington, DC. World Bank. https: //openknowledge.worldbank.org/handle/10986/26430 License: CC BY 3.0 IGO.

Zhang, X., T. Y. Qi, X. M. Ou, and X. L. Zhang (2017), "The Role of Multi-region Integrated Emissions Trading Scheme: A Computable General Equilibrium Analysis", Applied Energy, 185, 1860-8. 